\title{
Regional stratospheric warmings in the Pacific-Western Canada (PWC) sector during winter 2004/2005: implications for temperatures, winds, chemical constituents and the characterization of the Polar vortex
}

\author{
A. H. Manson, C. E. Meek, and T. Chshyolkova \\ Inst. of Space and Atmospheric Studies, University of Saskatchewan, 116 Science Place, Saskatoon, SK, S7N 5E2, Canada
}

Received: 20 November 2007 - Revised: 14 August 2008 - Accepted: 15 October 2008 - Published: 19 November 2008

\begin{abstract}
The vortex during winter 2004/2005 was interesting for several reasons. It has been described as "cold" stratospherically, with relatively strong westerly winds. Losses of ozone until the final warming in March were considerable, and comparable to the cold 1999-2000 winter. There were also modest warming events, indicated by peaks in $10 \mathrm{hPa}$ zonal mean temperatures at high latitudes, near 1 January and 1 February. Events associated with a significant regional stratospheric warming in the Pacific-Western Canada (PWC) sector then began and peaked toward the end of February, providing strong longitudinal variations in dynamical characteristics (Chshyolkova et al., 2007; hereafter C07). The associated disturbed vortex of 25 February was displaced from the pole and either elongated (upper) or split into two cyclonic centres (lower).

Observations from Microwave Limb Sounder (MLS) on Aura are used here to study the thermal characteristics of the stratosphere in the Canadian-US $\left(253^{\circ} \mathrm{E}\right)$ and Scandinavian-Europe $\left(16^{\circ} \mathrm{E}\right)$ sectors. Undisturbed high latitude stratopause $(55 \mathrm{~km})$ zonal mean temperatures during the mid-winter (December-February) reached $270 \mathrm{~K}$, warmer than empirical-models such as CIRA-86, suggesting that seasonal polar warming due to dynamical influences affects the high altitude stratosphere as well as the mesosphere. There were also significant stratopause differences between Scandinavia and Canada during the warming events of 1 January and 1 February, with higher temperatures near $275 \mathrm{~K}$ at $16^{\circ}$ E. During the 25 February "PWC" event a warming occurred at low and middle stratospheric heights (10$30 \mathrm{~km}: 220 \mathrm{~K}$ at $253^{\circ} \mathrm{E}$ ) and the stratopause cooled; while over Scandinavia-Europe the stratosphere below $\sim 30 \mathrm{~km}$
\end{abstract}

Correspondence to: A. H. Manson

(alan.manson@usask.ca) was relatively cold at $195 \mathrm{~K}$ and the stratopause became even warmer $(>295 \mathrm{~K})$ and lower $(\sim 45 \mathrm{~km})$. The zonal winds followed the associated temperature gradients so that the vertical and latitudinal gradients of the winds differed strongly between Scandinavia-Europe and Canada-US.

The data-archive of Aura-MLS was also used to produce height versus latitude contours of ozone and related constituents, using mixing ratios $(r)$ for $\mathrm{ClO}, \mathrm{N}_{2} \mathrm{O}$ and $\mathrm{HCl}$, for the $16^{\circ} \mathrm{E}$ and $253^{\circ} \mathrm{E}$ sectors. The Q-diagnostic was used to display the positions of the cyclonic (polar) vortex, using data from the UK Meteorological Office (MetO) analyses. ClO/HCL maxima/minima occurred on 1 February in both sectors, consistent with loss of ozone by heterogeneous chemistry. Low $\mathrm{N}_{2} \mathrm{O}$ values at high latitudes indicated that both sectors were inside the polar vortex, Time-difference plots show greater reductions in $\mathrm{O}_{3}$ in the Canadian sector. For the 25 February PWC warming event, $\mathrm{O}_{3}$-rich air from lower latitudes continued to be excluded from Europe, while $\mathrm{O}_{3}$ penetrated to at least $82^{\circ} \mathrm{N}$ over the Canadian sector. The contours for $\mathrm{ClO}, \mathrm{N}_{2} \mathrm{O}$ and $\mathrm{HCl}$ at $16^{\circ} \mathrm{E}$ are consistent with continued ozone loss within the vortex during the event.

Finally the thermal and chemical changes at these $16^{\circ} \mathrm{E}$ and $253^{\circ} \mathrm{E}$ sectors are placed into a hemispheric context using polar-cylindrical plots, with the following results. Firstly, the mixing ratios of $\mathrm{O}_{3}, \mathrm{ClO}, \mathrm{HNO}_{3}, \mathrm{HCL}$ and the temperatures from Aura-MLS were consistent with consensus views of heterogeneous chemistry. Secondly, and consistent with the polar plots of $\mathrm{C} 07$, the vortices and their edges were strongly distorted during the 1 January, 1 and 25 February warming events, with sinusoidal shapes consistent with stationary planetary waves of wave-numbers 1 and 2 . Thirdly, the distributions of the chemicals followed the curvatures (cyclonic and anticyclonic) of the vortex edges with

Published by Copernicus Publications on behalf of the European Geosciences Union. 
$\mathrm{O}_{3}$ losses occurring at the cold cyclonic locations. During February these were over Scandinavia-Western Europe and Central-Eastern Canada. Trajectory analysis was applied to the two February warming events. For the 1 February event, the rotation time for air parcels within the peanut-shaped vortex was 3-4 days; while the $\mathrm{O}_{3}$-rich low latitude air that entered the Pacific-Western Canada sector during the 25 February event, showed no signs of becoming trapped within the highly distorted but still strong remnant of the polar vortex.

Keywords. Meteorology and atmospheric dynamics (Middle atmosphere dynamics; Polar meteorology; Waves and tides)

\section{Introduction}

Approaches toward studies of temperature disturbances in the middle atmosphere $(20-100 \mathrm{~km})$ are still coloured by the backgrounds of the scientists and the techniques available for them. The authors of this paper began their research with medium frequency radars, measuring electron densities or winds (60-90 km), and establishing relationships between planetary waves of the lower stratosphere and associated variabilities in the mesosphere-lower thermosphere (MLT). The studies have become more global with time (Gregory and Manson, 1970, 1975; Labitzke et al., 1987; Manson et al., 2002, 2005; Chshyolkova et al., 2005, 2006, 2007, 2008). While ground-based observations continue to have great value due to their high time resolution, especially when networks are available, studies that also include global satellite observations are now of greatest value. For example, Labitzke et al. (1987) compared geostrophic winds from satellite radiances at $80 \mathrm{~km}$, for the first time, with measured radar winds. The turning of the observed wind vector into the low pressure of the vortex system was consistent with a mesospheric friction-force and hence the momentum-drag due to dissipating gravity waves (GW).

Most recently, after $\sim 15$ years of GW, tidal and planetary wave studies, we as Canadians have begun to focus more on the winter polar vortex and associated global coupling processes. Increasingly our studies incorporate satellite data (e.g. TOMS - Total Ozone Measuring System) and data from GCMs using data assimilation (e.g. United Kingdom Meteorological Office (MetO) analyses). In particular Chshyolkova et al. (2006) demonstrated that the 7 month intervals of middle to high latitude westerly winds, which are associated with the winter polar vortex, provide 1-2 equinoctial months when the global middle atmosphere winds are westerly. Planetary Waves (PW) of 12-16 day period exist in both hemispheres and typically from $20-90 \mathrm{~km}$ during these times. Further impetus comes from the Scientific Committee on Solar-Terrestrial Physics (SCOSTEP) Coupling and Weather of the Sun-Earth System (CAWSES) program that includes a project on the middle atmosphere wind systems: "Atmospheric Wave Interactions with the Winter Polar Vortices (0-100 km)" with Coordinator Alan Manson. A complementary initiative is the new Canadian Network for the Detection of Atmospheric Change (CANDAC) Polar Environment Atmospheric Research Laboratory (PEARL) at Eureka $80^{\circ} \mathrm{N}$, Ellesmere Island. The operation of a meteor radar at PEARL, two other Canadian meteor radars at northern latitudes (Yellowknife and Resolute Bay; Hocking, 2001), plus the MF radars at Saskatoon $\left(52^{\circ} \mathrm{N}\right)$ and at Platteville $40^{\circ} \mathrm{N}$; Manson et al., 2003) provide a very substantial data archive of wind data for the Canada-US sector. Collaborations involving additional radars in Japan (Wakkanai $\left(45^{\circ} \mathrm{N}\right)$, Yamagawa $\left(31^{\circ} \mathrm{N}\right)$ ) and eastern-Canada (London $\left(43^{\circ} \mathrm{N}\right)$ ), have provided evidence for longitudinal and latitudinal variations in mean winds and associated planetary and gravity wave activity for the Canada-Pacific sector (Manson et al., 2004).

The most recent of our papers (C07) is a study of the "Polar Vortex Evolution during Northern Hemispheric Winter 2004/2005": that year featured the first Campaign of the CAWSES project on Winter Vortices. Data were from 12:00 MLT radars, the MetO globally assimilated fields and Aura-MLS temperatures. Analyses included the Qdiagnostic for characterization of cyclonic and anti-cyclonic structures (Harvey et al., 2002), which gave excellent clarity on longitudinal and altitudinal variability. The winter vortex was very cold with no major SSW, which is consistent with the westerly phase of the Quasi Biennial Oscillation (QBO) under Solar Minimum conditions (Labitzke, 2006). However, there were three intervals with rapidly increasing high latitude $10 \mathrm{hPa}$ zonal mean temperatures and related weakening of the zonal mean winds; two events were near 1 January and 1 February, with the largest disturbance near 25 February. Despite the absence of a midwinter major sudden warming the cyclonic "vortex was elongated, slightly shifted (with respect to the pole), had a westward tilt with height, and had decreased in area in the lower stratosphere" during the 3 disturbances (C07); and during the last event the vortex "was divided into two unequal parts below $24 \mathrm{~km}$ ". Singleton et al. (2007) also described it thus. The strong intensification of the Aleutian anticyclone (AC), with a reversal of the lower stratospheric temperature gradient toward the pole, are traditional conditions for so-called "Canadian Warmings", but this event failed to meet all of the criteria (Labitzke, 1977) and it is not listed in the meteorological website of the Free University of Berlin. Instead we call it a regional stratospheric warming in the "Pacific-Western Canada" (PWC) sector, which is actually a better title, given the location of the Aleutian AC. Height versus latitude plots of the Scandinavia-Europe and Canada-US sectors showed dramatic differences in the positions of the vortex, directions of zonal winds in the lower and middle atmosphere (0$97 \mathrm{~km}$ ), gradients of potential vorticity and the heights and intensity of PW. We noted in $\mathrm{C} 07$ that a related chemical study for 2004/2005 vortex was ongoing. 
In the light of the above discussions, the present study of the 2004/2005 vortex has a number of important aims or goals. Using Aura-MLS temperature-data we investigate the thermal characteristics of the lower and middle atmospheres and northern latitudes for the Canada-US sector through Saskatoon $\left(253^{\circ} \pm 12^{\circ} \mathrm{E}\right)$ and the Scandinavia-Europe sector through Tromso $\left(16^{\circ} \pm 12^{\circ} \mathrm{E}\right)$. (We note that the title "Earth Observing System", EOS, is often used alongside MLS; we shall usually write Aura-MLS.) Changes in temperatures for the stratopause and tropopause regions are know to be important during warming events (Labitzke, 1972), and the changes in the middle atmosphere winds for the three warmings in January and February are already known to be significant (C07). This is an excellent opportunity, and our first aim, to use the exceptional data archive from Aura-MLS (Sect. 3) to investigate the thermal changes in the two sectors. The winds from MetO are also used, for both 2004/2005 and 2005/2006 vortices, to compare lower and middle atmosphere winds with the two classifications provided by Abatzoglou and Magnusdottir (2007). They have claimed that PW breaking events are accompanied with unique atmospheric climatologies, depending on whether they occur in the upper or lower part of the vortex (Sects. 4 and 7). Our third goal is to use Aura-MLS chemical mixing ratios, for ozone, $\mathrm{ClO}, \mathrm{N}_{2} \mathrm{O}$ and $\mathrm{HCl}$, to assess and distinguish the changes and potential losses of ozone in the Canada-US and Scandinavia-Europe sectors, in particular during the regional mid-warmings of 1 January, 1 and 25 February (Sect. 5). Regions of the height versus latitude plots for which the Qdiagnostic is negative, and hence part of cyclones (the vortex) and anticyclones, are assessed for heterogeneous chemical processes, and therefore for ozone losses. Presently, as noted below, several of the excellent published studies have focused mainly upon ozone losses in Scandinavia, or have used equivalent latitudes enroute to assessments of hemispheric losses during the 2004/2005 winter, and up to the final warming in March. Fourthly, we place the Aura-MLS chemicals in hemispheric context, using polar-cylindrical plots (Sect. 6). The edges of the vortices, coming from Q-diagnosis, are compared to the mixing ratios of ozone-related chemicals, and favoured positions for heterogeneous chemical destruction of ozone are sought, in the context of the shape and location of the vortices. Finally and fifthly, trajectory analysis is part of Sect. 6, and is used to assess air-parcel motions both outside and inside the vortices of the 1 February event. It provides a fifth aim or goal within the hemispheric context. Our particular interest for the 25 February event is whether ozone-rich air from low latitudes, which is advected as far north as $82^{\circ} \mathrm{N}$ in the Pacific-Western Canada sector, penetrates the edge of the highly distorted and displaced (to the Scandinavian sector) vortex.

There have been several outstanding and recent papers published during the 2006/2007 years which we have used either as starting points for this study, or as a stimulus to assess important processes occurring during our winter of first choice. Linkages with the present study are mentioned after each one.

Manney et al. (2006) provided the first application of Aura-MLS data, featuring mainly ozone and nitrous oxide $\left(\mathrm{N}_{2} \mathrm{O}\right)$, for the winter polar vortex of 2004/2005. Their figure of four pairs of polar plots for key days of the three temperature disturbances plus a spring day indicates the high variability of the position, elongation and structure of the vortex and the corresponding $\mathrm{O}_{3}$ and $\mathrm{N}_{2} \mathrm{O}$ mixing ratios, $r$. Their subsequent use of equivalent latitude, which is the latitude enclosing the same area as the vortex-edge contour, led to discussions of various events. These latter involved changes of $r\left(\mathrm{O}_{3}\right)$ and $r\left(\mathrm{~N}_{2} \mathrm{O}\right)$ with height at the edge as well as innercore of the vortex. Estimates of $\mathrm{O}_{3}$ losses indicated that these were considerable, but less than predictions, and were due to enhanced mixing, dynamical complexities and an early final warming (10-15 March). Additional aspects of the thermal and dynamical characteristics of the polar and middle latitudes affected by the highly variable vortex are discussed in the present paper.

Aura-MLS observations of dehydration for this same very cold Arctic winter provided evidence (Jimenez et al., 2006) that "only one single event of depleted water vapour on 2527 January was linked to the likely formation of ice". The Single Layer Isentropic Chemistry And Transport (SLIMCAT) Chemical Transport Model (CTM) and reverse trajectory calculations were used, and the location was Spitsbergen in northern Norway. An aircraft flight (Geophysica; von Hobe et al., 2006) on 7 March provided evidence for $90 \%$ chlorine-activation and up to $60 \%$ ozone-loss, reflecting extensive Polar Stratospheric Cloud (PSC) formation in the stratosphere during the winter; and also inferring significant denitrification. Our study places Spitsbergen within global chemical and dynamical fields.

Three papers from 2007 are of specific relevance here also. Grooß and Müller (2007) have simulated ozone depletion during the Arctic winter 2004/2005 using the Chemical Lagrangian Model of the Stratosphere (CLaMS). They note the relative uniqueness of this winter due to a "second transport barrier" that existed at the time of vortex formation, which led to an inhomogeneous ozone distribution. This complicates estimates of $\mathrm{O}_{3}$ loss, and was thought to explain their simulated loss (69 DU on 23 March, 380-550 K), which was lower than other estimates for this year. In this paper we pursue aspects of the thermal and dynamical characteristics of the polar vortex that provided the vortex-complexity noted by Grooß and Müller (2007). Secondly we mention the comprehensive study by Singleton et al. (2007) which quantified inferred ozone loss during the 2004/2005 winter using differences between observations from Aura-MLS plus four solar occultation satellite instruments and passive $\mathrm{O}_{3}$ values from SLIMCAT-CTM. The vortex was characterized using the Qdiagnostic and the modeled ozone losses use the CTM chemical and passive ozone fields. Although some discrepancies remained, the authors considered that the CTM had provided 
satisfactory simulations of $\mathrm{O}_{3}$ losses during this challengingly dynamical Arctic winter. They concluded that the inferred $\mathrm{O}_{3}$ losses were slightly less (values of circa $100 \mathrm{DU}$ for the height range $575-400 \mathrm{~K}$ at the end of March) than during the 1999/2000 winter, and that modeled loss-values at typical heights were only $10-15 \%$ larger. Finally, Feng et al. (2007) used the SLIMCAT 3-D CTM to quantify Arctic losses in 2004/2005 and compared them with years from 1994/1995 to 2005/2006. The model produced "large regions of possible NAT (nitric acid trihydrate) and ice PSC formation", and "strong denitrification, extensive chlorine activation and large chemical ozone loss of up to $75 \%$ locally and $\sim 140 \mathrm{DU}$ in the vortex-averaged column" (slightly larger than observed). They noted that the short lived vortex in March likely minimized ozone losses after the 25 February temperature disturbance. We do not intend to attempt a similar study of the magnitude demonstrated by these three papers, but rather to highlight some of the significant characteristics of this winter of complex vortex behaviour, especially for the Scandinavian and Canadian sectors, which were unintentionally obscured in the three fine papers. Their intentions were to obtain estimates of hemispheric ozone losses, which is valuable and required societal information. Our intention, which includes the five aims or goals provided earlier, is to display and discuss the extraordinary longitudinal variations in thermal conditions, winds, chemicals and vortex structure during this winter of 2004/2005. Such an approach makes every winter vortex, of either hemisphere, interesting in its own right, whether or not there is ozone loss.

Three other recent and more general papers, which highlight processes that modify ozone mixing ratios inside and outside (middle latitude) the polar vortex, have influenced our thinking as this paper was developed. Akiyoshi et al. (2006) discuss the effects of polar ozone depletion on middle latitude ozone after the spring breakup (1997 Arctic). Tilmes et al. (2006) detail the chemical ozone loss during the "setup" phase of the polar vortex (the Arctic-autumn of 2003), the competing roles of ongoing radical catalytic cycles and decreasing solar illumination on ozone losses, and wave-driven transport of ozone-rich air from lower latitudes. Correlations of $\mathrm{O}_{3} / \mathrm{N}_{2} \mathrm{O}$ were quite "compact" by the end of October, consistent with isolation and good mixing of $\mathrm{O}_{3}$ in the vortex. Salby and Callaghan (2007) provide a complementary and elegant presentation on the two mechanisms that control winter-time mixing ratios of ozone: “... Anomalously weak residual mean winds (associated with PW dissipation) result in anomalously weak ozone transport into the Arctic. It is attended by anomalously cold temperatures, which ... supports PSC and anomalous chemical destruction. Both ... reduce winter-time increase of Arctic ozone." The above conditions are met preferentially during the westerly phase of the QBO (Holton and Tan, 1980; Labitzke et al., 2006). We are reminded that isentropic mixing by PW, especially in March/April, provides poleward transfer of ozoneenriched air that has arrived on isentropic surfaces by down- welling; and that transfers into the general Arctic regions are to be distinguished from horizontal transport into the vortex. Salby and Callaghan (2006) also properly and powerfully remind us that seasonal transience plays a major role in driving residual mean motion and ozone transport: they conclude "that even in the absence of wave driving, there would still exist a substantial wintertime increase of total ozone" at middle to high latitudes. At $60 \mathrm{~N}$, the "wintertime increase of total ozone between the autumnal equinox and early January" maximizes, and "only 20\% of that increase is derived from planetary wave drag".

\section{Data sources, characterizations and analyses}

The data used in this work are from the same sources as those in $\mathrm{C} 07$, so only brief remarks are made here.

\subsection{MetO data}

The MetO data (also known as UKMO, United Kingdom Meteorological Office) are the result of assimilation of operational meteorological measurements from satellites, radiosondes and aircraft into a numerical forecasting model of the stratosphere and troposphere. A 3-D variational (3DVAR) data assimilation system (Lorenc et al., 2000) is used. After October 2003 a new version was introduced and three more levels (up to $0.1 \mathrm{hPa} \approx 64 \mathrm{~km}$ ) added to the existing 22 standard UARS (Upper Atmosphere Research Satellite) pressure levels. The outputs of the model with data assimilation are global fields of daily temperatures, geopotential heights and wind components. There are 72 latitudes and 96 longitudes with $2.5^{\circ}$ and $3.75^{\circ}$ steps in latitude and longitude, respectively. We use MetO temperatures and horizontal wind components to describe the state of the stratosphere and to calculate the Q-diagnostic (Sects. 2 and 3 below).

Model inter-comparisons (Randel et al., 2004) have shown modest biases for MetO: cold temperature-biases $(\sim 5 \mathrm{~K})$ near the stratopause and a warm tropical tropopause temperature $(\sim 1-2 \mathrm{~K})$. Since then there have been improvements in the model and assimilation technique. MetO data are widely used for studies of the stratospheric region e.g. O'Neill et al. (1994) successfully studied the Arctic stratosphere for 1991/1992. We have also used MetO data in conjunction with TOMS (Total Ozone Mapping Spectrometer) and MF radar data in earlier studies (Chshyolkova et al., 2005, 2006).

\subsection{Aura data}

In this paper we have used both temperatures and chemical mixing ratios from the Microwave Limb Sounder (MLS, Waters et al., 2006) onboard the National Aeronautic and Space Administration (NASA) Aura satellite. The Aura spacecraft was launched on 15 July 2004 on a 705-km sun-synchronous near-polar orbit with a 98.2 inclination. It has a 16-day "repeat cycle" and 233 revolutions per cycle. The daily data 
are available for the $316-0.001 \mathrm{hPa}(\sim 8-97 \mathrm{~km})$ altitude region and have coverage from $82^{\circ} \mathrm{S}$ to $82^{\circ} \mathrm{N}$ latitudes (in 121 "bins") on each orbit with longitudinal and vertical resolutions of $250 \mathrm{~km}$ and $4 \mathrm{~km}$, respectively. The first validation results of Froidevaux et al. (2006) show that temperatures and mixing ratios of $\mathrm{O}_{3}, \mathrm{H}_{2} \mathrm{O}, \mathrm{N}_{2} \mathrm{O}, \mathrm{HCl}, \mathrm{HNO}_{3}$, and $\mathrm{CO}$ agree well with other satellite and meteorological datasets, as well as with balloon-measurements in the stratospheric and mesospheric regions. This paper was completed using Aura-MLS data in version 1.5 form, as version 2.2 data were not all available. However subsequent assessment of the key dates used here show only modest differences, which are insignificant for Sects. 5 and 6 and the concluding Summary.

\subsection{Analysis}

To characterize the winter polar vortex the "Q-diagnostic" has been chosen and the algorithm developed by Harvey et al. (2002) was closely followed. The Q-diagnostic includes calculation of the scalar quantity $Q$, the stream-function $(\psi)$, the relative vorticity $(\zeta)$, and integration of $Q, \zeta$, and winds along $\psi$ isopleths. $Q$ is "a measure of the relative contribution of strain and rotation in the wind field" (Fairlie, 1995), where rotation dominates the flow for negative $Q$. Thus, negative $Q$ is associated with stable rotational flow (Babiano et al., 1994) and is observed to be spatially dominant inside vortices. In contrast, shear-zones beyond the edges of vortices, occasional relatively small regions within vortices, and near strong winds in the troposphere and lower mesosphere may have positive $Q$, which is an indication of "strain" dominating over "rotation". Therefore, for identification of the vortex "edges", streamlines with integrated values of $Q$ (along the streamline) closest to zero and with the strongest integrated winds are chosen; integration of relative vorticity distinguishes cyclonic and anticyclonic vortices (Fairlie, 1995; Harvey et al., 2002).

Isentropic trajectories are based on MetO horizontal winds ( $u$, zonal speed; $v$, meridional speed). MetO horizontal wind and temperature grids are offset. For our purposes they are required to be on the same grid, so the temperature grid is translated to the wind positions by averaging the four temperatures at the corners of each cell. Isobaric horizontal winds and temperature data are then interpolated to potential temperature (PT) surfaces. Then a set of initial "parcel" locations are chosen (usually on a series of fixed latitude circles; Sect. 6) and followed in time by applying local $u$ and $v$ to the present position over a small time step. The time step is varied during the analysis so that a single step does not move any parcel across more than $1 / 2$ cell. Local $u$ and $v$ at a particular location and time are found by what we will call "tri-lateral patch" or "tri-linear interpolation"; viz. for $u$ :

$u=a x+b y+c t+d x y+e y t+f t x+g x y t+h$,

where $x, y, t$ are spatial and time locations in the present cell, and $a, b, c, d, e, f, g, h$ are exactly determined from the MetO data i.e. the selected PT surface and the $u$ values at the corners of the cell. Near the pole, where spherical trigonometry is inaccurate, the velocity vector (relative to the earth) is frozen until the particle leaves the area. The same method can be used for forward or reverse trajectories, but the former is more useful here. A major reason being that the motions and positions of parcels are required for intervals throughout the various disturbances of temperatures and vortex, or events, and the program allows parcels to be placed anywhere, inside, outside or on the edge of the vortex.

\section{Temperatures}

Temperatures from Aura-MLS have been contoured in height versus northern latitude plots (pressure-height is converted to approximate kilometers using CIRA-86 winter values versus northern latitude) for particular events (3 day means, centred on the day of interest) and longitudes appropriate to Canadian Prairies (Saskatoon $253^{\circ} \pm 12.5^{\circ} \mathrm{E}$ ) and Scandinavia (Tromso $16^{\circ} \pm 12.5^{\circ} \mathrm{E}$ ). The means for the $25^{\circ}$-sectors and also the zonal means are shown (Fig. 1). The days are chosen from $\mathrm{C} 07$, which identified three dates near the end of warming trends or "temperature disturbances" (typically $\sim 10$ days in duration) as indicated by zonal mean MetO temperatures at $60-70^{\circ} \mathrm{N}$ and $10 \mathrm{hPa}$. Zonal mean winds at the same latitudes and height had also decreased on those dates. The vortex characterizations (shape and position) by the Q-diagnostic (their Fig. 4) were also noted to be zonally asymmetric throughout the stratosphere. The vortex edges for 25 December and for the 1 January and 1 February events are close to $45^{\circ} \mathrm{N}$ near $50 \mathrm{~km}$ and $50-60^{\circ} \mathrm{N}$ near $30 \mathrm{~km}$ at both sectors in Fig. 1, despite there being differences in the shapes and locations of the hemispheric vortex on those dates. The 25 December temperature contours are the result of a symmetrical and cone-shaped vortex in the 20$50 \mathrm{~km}$ height range, and are similar in that sense to the many other non-disturbed days in mid-January or mid-February. The vortex at $20-50 \mathrm{~km}$ was of distorted elliptical shape on 1 January and peanut shaped on 1 February, with strong anticyclones at Eurasian longitudes on both dates; the vortex also rotated with height toward the west. The 25 February event refers to a 10 day interval when the largest mid-winter warming occurred; we call this the regional stratospheric warming in the "Pacific-Western Canada" (PWC) sector. The stratosphere below $\sim 32 \mathrm{~km}$ in the Canadian sector and latitudes is significantly warmer than on any of the other days/sectors in Fig. 1, and the vortex edge did not cross that longitudinal sector. Over Scandinavia, the lower stratosphere remains cold and the vortex edge is at $\sim 50^{\circ} \mathrm{N}$. The vortex was then strongly elongated, rotated westward with height, and displaced from the pole at all upper levels $(>700 \mathrm{~K})$. The Q-diagnostic showed the vortex to be broken into two parts in the lower stratosphere (as also noted by Singleton et al., 2007), with the larger portion over Europe; a plot of 

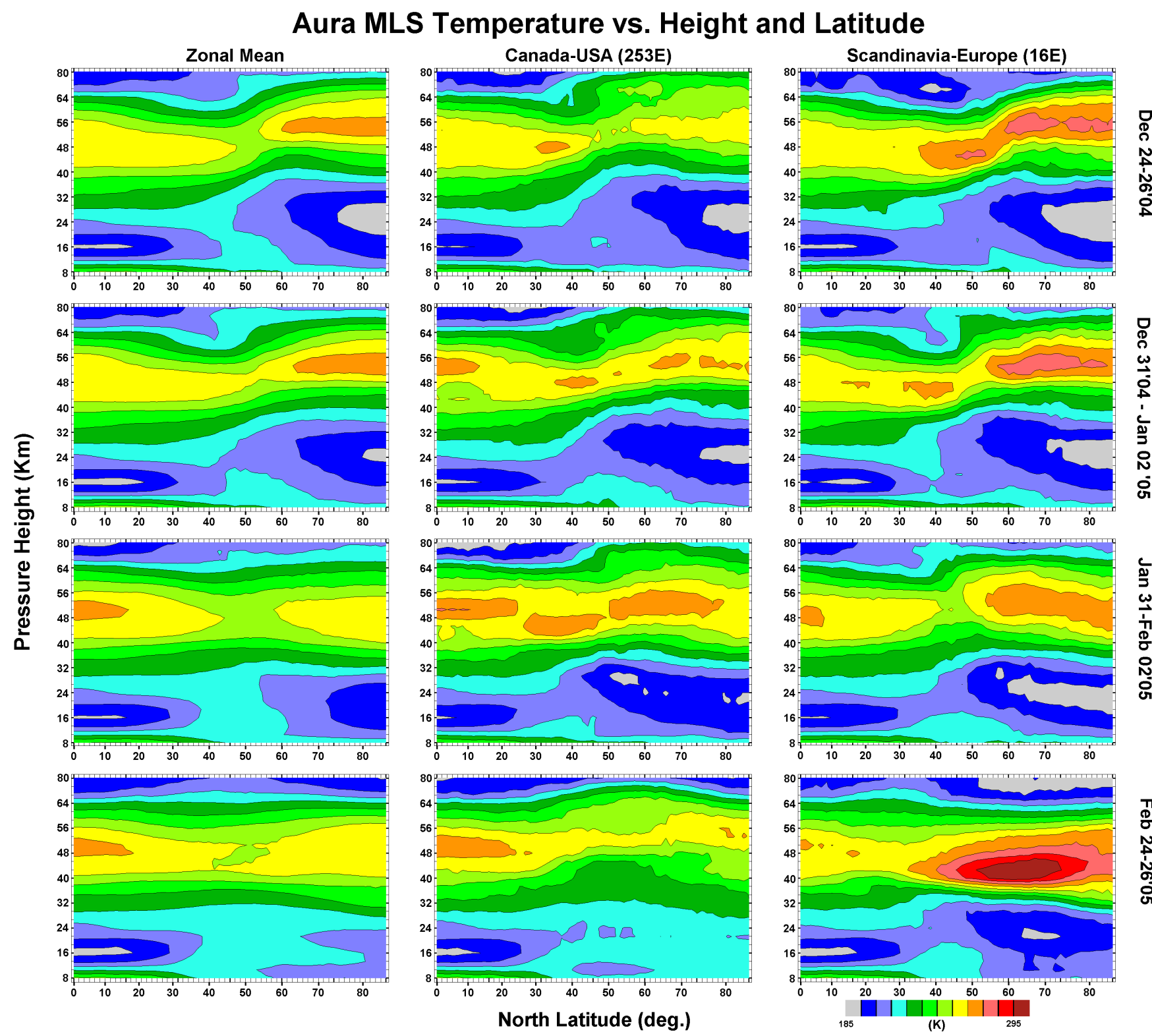

Fig. 1. Aura MLS middle atmosphere temperatures for four time-intervals and at two longitudinal locations plus the zonal mean during winter 2004/2005. The longitudinal sectors are of $25^{\circ}$ width.

potential vorticity at those heights was not split into two, but was shaped like a dumbbell.

Comment on the robustness and representative nature of these plots is appropriate, given the remarkably high polar stratopause temperatures. The shapes and positions of the contours for the stratopause and tropopause during each of the 4 days in Fig. 1 were basically reproduced using data from SABER-TIMED (Sounding of the Atmosphere using Broadband Emission Radiometry; Thermosphere, Ionosphere, Mesosphere, Energetics and Dynamics). Also, contour plots based on MLS data for a range of longitudes (240$315^{\circ}$ E, Canadian Rockies to Maritimes) are similar to those for $253^{\circ} \mathrm{E}$ in Fig. 1, and typically at least a $0-45^{\circ}$ range of longitudes in Europe have contour plots similar to those for $16^{\circ} \mathrm{E}$ in Fig. 1. Plots produced from MetO are also very similar to Fig. 1: the 3 plots for 25 February are well reproduced, but on some other days and geographical locations the polar elevated stratopause was not reproduced. We discuss this in a later section.

The reader will have already ascertained some striking features from Fig. 1, the dominant being a warm winter polar stratopause, which is also often at an altitude higher than at low latitudes (equator to $40^{\circ} \mathrm{N}$ ). One or both of these features occurs in every panel of Fig. 1. This has not been an 
obvious part of empirical models or of a number of General Circulation Models. For example, only a very careful inspection of CIRA-86 reveals minute portions of such higher valued contour lines near the pole in November-March (Northern Hemisphere). This absence of a clearly evident warm stratopause at often elevated heights, from $\sim 50^{\circ} \mathrm{N}$ to $85^{\circ} \mathrm{N}$, may be due to averaging of data (over longitudes and time), which at some heights and latitudes may also have been limited in quantity.

This warm polar stratopause feature in MLS data was also quite evident upon inspection of some other days between the disturbances (e.g. mid-January, and mid-February), as expected since they were earlier typified as being similar in vortex-character to the 25 December example of a stable and "cold" vortex. The warm winter polar mesosphere, in comparison with the low latitude mesosphere, is evident in Fig. 1 as expected, but the positive northward temperature gradients in the stratopause region will also provide easterly thermal winds from lower heights than traditionally expected. These thermal winds will now begin in the upper stratosphere as low as $40 \mathrm{~km}$, but more typically $55 \mathrm{~km}$ in zonal mean and Canadian and Scandinavian sectors.

It is important to mention the sequences of rockettemperature profiles shown by Labitzke (1972) for West Geirinish (57 ${ }^{\circ}$ N; $1967 / 1968$ and 1968/1969 winters). There, very sharply peaked stratopauses with temperatures $\geq 270 \mathrm{~K}$ and cool lower stratospheres existed before the stratopauseregions cooled and the "stratospheric-warmings" reached $20-30 \mathrm{~km}$. Thereafter, breakdowns of the westerly circulation occurred. This is quite similar to the scenario for the Canada-USA sector from 1 February to 25 February (Fig. 1). Indeed given that the latitudes involved are part of the polar night the regions with enhanced temperatures near $40-50 \mathrm{~km}$ are not part of a chemical or radiational stratosphere but must be associated with dynamic processes. We also note, following Siskind et al. (2007), that the warm or "separated" winter polar stratopause was discussed in some detail by Hitchman et al. (1989), in which decade GW-forcing of the zonal flows and hence the concepts of driven poleward meridional winds and descent of high latitude air-parcels were conceptually in their infancy. They used Nimbus data to demonstrate the warm polar middle atmosphere, and a 2-D model including GW to illustrate the process effectively. The averaging of Nimbus data over several years within CIRA-86 effectively smoothed out or minimized (as noted in the paragraph above) this temporally varying process. Also, GCM developments over the last decade or so, and associated GW parameterizations, have tended to focus on tuning to provide appropriate mesopause temperatures and thence closure of the upper parts of the summer and winter middle to high latitude zonal vortices. We may expect that as data assimilation is increasingly applied to middle atmosphere GCMs, the relationships between the most recently observed warm-elevated polar stratosphere and planetary/gravity waves fluxes will be explored and better understood. At this stage, and based upon the time progression in Fig. 1, it appears that the elevation of the stratopause is at its greatest early in the winter (25 December) when the vortex was symmetrical, strong and "cold".

Finally, time sequences of temperatures are shown for troposphere to mesosphere altitudes over Canada and Scandinavia-Europe (Fig. 2) at six locations: Saskatoon $52^{\circ} \mathrm{N}$, Yellowknife $62^{\circ} \mathrm{N}$, Resolute Bay $75^{\circ} \mathrm{N}$; Collm $51^{\circ} \mathrm{N}$, Sweden $60^{\circ} \mathrm{N}$ and Tromso $70^{\circ} \mathrm{N}$. For each location the longitudinal width is $\pm 12.5^{\circ}$ and the latitudinal width is $\pm 1^{\circ}$. The differences in the evolution of the temperatures are striking, with very warm stratopause and cold lower stratosphere persisting over Europe-Scandinavia throughout the winter (October to mid-March). Consistent with discussions of the winter vortices above, and the figures in $\mathrm{C} 07$, the three locations in Scandinavia-Europe were inside the vortex at lower and middle (20-35 km) stratospheric heights throughout January and February. During February, as the lower stratosphere over Canada began to warm (Fig. 2) the vortex twisted westward at upper heights, so that by 25 February and above $1400 \mathrm{~K} / 40 \mathrm{~km}$ it was over the Canada-Pacific sector (C07). After that the stratosphere below $\sim 35 \mathrm{~km}$ at the three locations in Scandinavia-Europe remained in the vortex until near the final warming ( $\sim 11$ March), while the vortex above was more variable in position but was often westward and toward the Canada-Pacific sector. Over Canada the stratopause was less warm and often higher in height, with an often warmer ("green" color) lower stratosphere (Fig. 2); the latter being the case from October to mid-December, and then from mid-February. For the dates discussed in connection with Fig. 1, all three Canadian locations were inside the vortex, at lower and middle stratospheric heights, from December until mid-February, when the largest stratospheric warming in the Pacific-Western Canada (PWC) sector began to evolve. Visually, the six locations of Fig. 2 are inside the vortex when the lower stratosphere is "blue" in color and cold. Also in Fig. 2 there is a tendency, in the $16^{\circ} \pm 12.5^{\circ} \mathrm{E}$ sector, for the events of 1 January, 1 and 25 February to be associated with higher stratopause temperatures.

In general, the height of the stratopause decreases from December to March, and is more easily identified over the Scandinavian sector, with further suggestions of the stratopause layer increasing in thickness. The questions raised by the data presentations provided in Figs. 1 and 2 will likely be answered by detailed analyses of data from advanced GCMs with data assimilation.

\section{Background winds}

Following the discussions in Sect. 2 and in C07, changes in the shape and location of a vortex can be expected to lead to changes in the character of winds at particular locations (latitude and longitude). Hemispheric asymmetry of the zonal winds is expected to be apparent during the events 


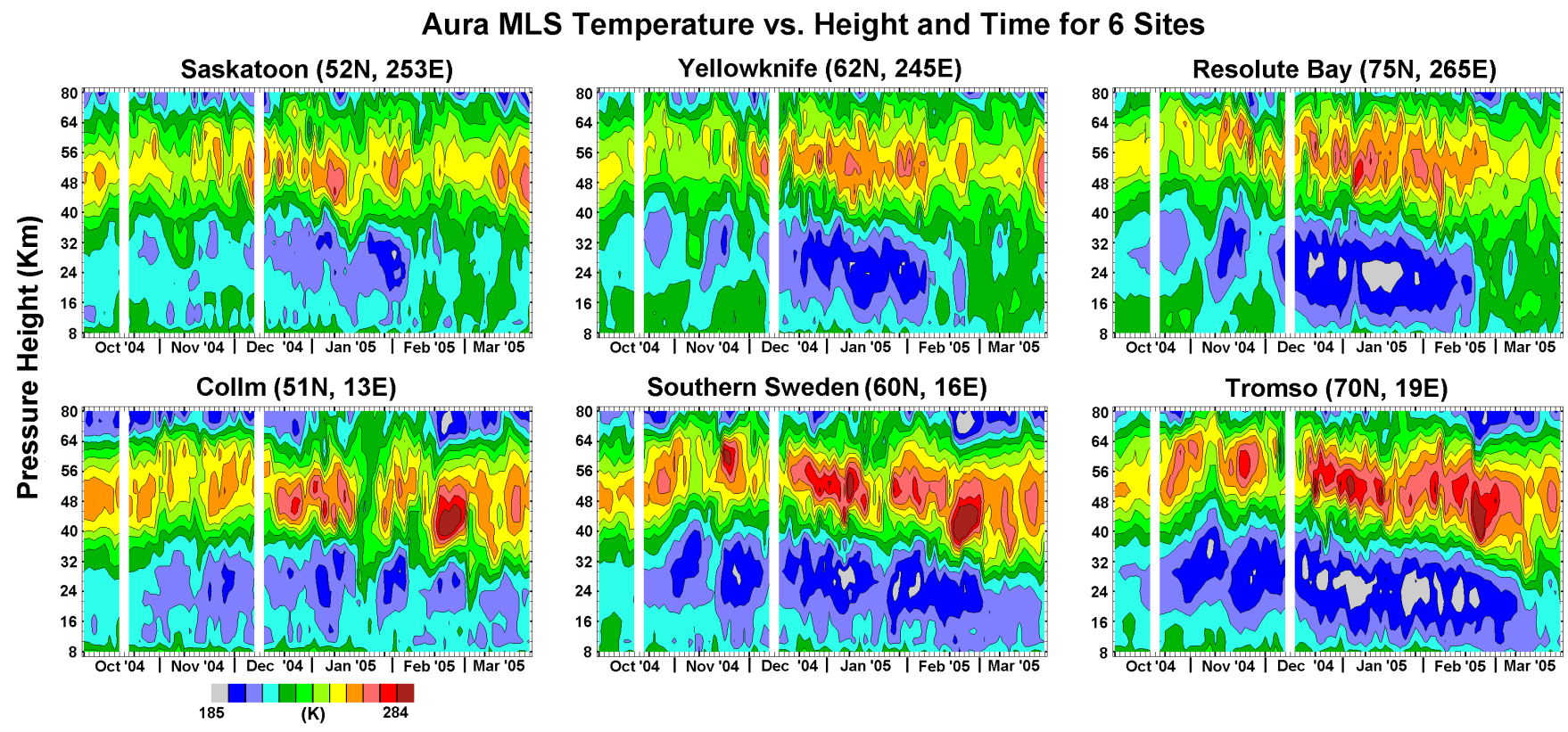

Fig. 2. Temperatures (Aura MLS) for three locations during the winter of 2004/2005 in each of the Canada and Scandinavia-Europe sectors: the locations-sizes are $25^{\circ}$ in longitude and $1^{\circ}$ in latitude.

of 1 January, 1 and 25 February. Wind magnitudes and directions may change throughout the middle atmosphere $(20-100 \mathrm{~km})$ as a function of longitude. Thus the normal (undisturbed) stratospheric westerly winds of higher latitudes $\left(>30^{\circ} \mathrm{N}\right)$ will not only weaken near the pole (e.g. as in CIRA-86) but will reverse over a significant height range for any group of days at locations that experience warmer temperatures to the north. Such gradients provide easterly thermal winds. Figure 6 of $\mathrm{C} 07$ provided winds from 0 $97 \mathrm{~km}$ for Svalbard $78^{\circ} \mathrm{N}$ and Resolute Bay $75^{\circ} \mathrm{N}$ : below $55 \mathrm{~km}$ these were from MetO, up to $80 \mathrm{~km}$ they were thermal winds from Aura-MLS temperatures, and above $80 \mathrm{~km}$ they were from radars. The easterly winds occurred spasmodically and especially near 1 January, 1 February, 25 February and throughout March. This was for $20-50 \mathrm{~km}$, increasingly for $55-80 \mathrm{~km}$, and even above $80 \mathrm{~km}$.

We show in Fig. 3 height versus latitude contour plots for the Scandinavia-Europe $\left(16 \pm 12.5^{\circ} \mathrm{E}\right)$ and Canada-US $\left(253 \pm 12.5^{\circ} \mathrm{E}\right)$ longitudes on 1 February (left) and 25 February (right). The $Q$ parameter (dark grey is negative where "solid rotation" dominates) and zonal winds (positive is westerly, out of the plane of the figure) are provided. The rotation was cyclonic (capital $\mathrm{C}$ in figure) in both sectors on 1 February, with the edges of the hemispheric vortex near the southern boundaries of the areas with negative values of $Q$. Although the stratospheric temperature disturbance on this day was relatively weak (a change of circa $5 \mathrm{~K}$ in 7 days for the $10 \mathrm{hPa}$ zonal mean at $60^{\circ} \mathrm{N}$ ), the vortex became elongated throughout the stratosphere (C07), was not centered on the pole, and the westerly circulation over Scandinavia-
Europe and Canada-US was effectively pushed to lower latitudes. As shown in Fig. 3, a zone of easterly winds is dominant from area $70^{\circ}$ to $90^{\circ} \mathrm{N}$. Because of this displacement, stratospheric winds in the middle to upper stratosphere flowed across the pole from Europe-Russia to the Pacific sector. This vortex distortion was associated with an increase in the amplitude of the stationary planetary wave (SPW 1) throughout the stratosphere at $60^{\circ} \mathrm{N}(\mathrm{C} 07)$ and the related intensification of the Aleutian anticyclone (AC). We will discuss the distribution of chemicals within the vortex for the 1 February event in Sect. 6.

An even more substantial range of polar latitudes, especially large over Canada, experienced strong easterlies on 25 February during the largest regional stratospheric warming in the Pacific-Western Canada (PWC) sector. The high latitude $\left(75^{\circ} \mathrm{N}\right)$ negative $Q$ region is imbedded in an $\mathrm{AC}$ (Fig. 3) for the sector centred on Saskatoon $\left(253^{\circ} \mathrm{E}\right)$ and is accompanied by a wind system of cyclonic rotation that maximizes in strength near $50 \mathrm{~km}$ and centred near $35^{\circ} \mathrm{N}$. This system extended from central Canada to the eastern $\mathrm{Pa}$ cific and dominated the $180^{\circ} \mathrm{E}$ to $360^{\circ} \mathrm{E}$ sector. In contrast, over Scandinavia-Europe the cyclonic vortex maximized near $36 \mathrm{~km}$ and $45^{\circ} \mathrm{N}$. The southern boundary of this cyclonic area was again very close to the edge of the hemispheric polar vortex. Great care is required in interpreting such $16^{\circ} \mathrm{E}$ zonal wind data, due to the displaced polar vortex. Specifically, in the context of the polar vortex and its edge (from C07: the streamline with "integrated $Q$ near zero and the strongest winds"), the vortex and its edge at mid to low stratospheric heights were completely in the large sector 
February 1, 2005

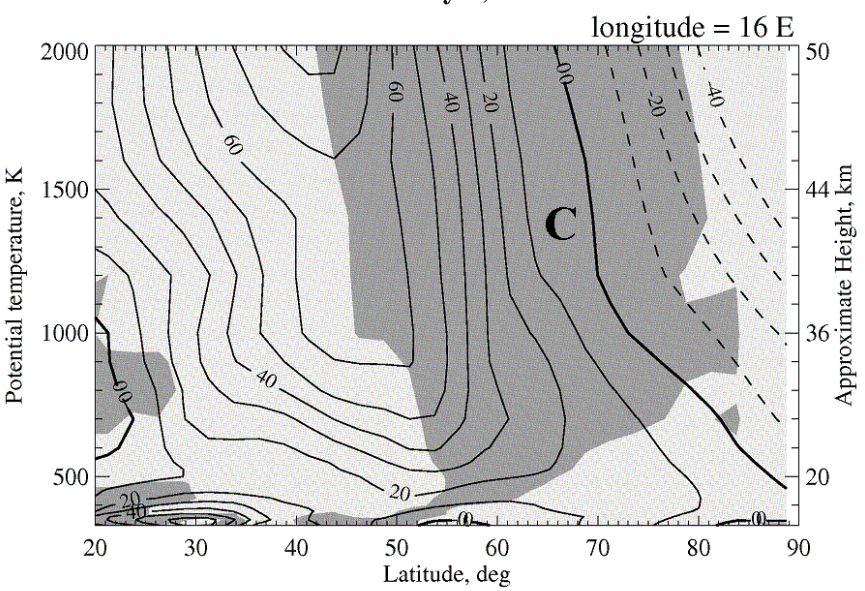

longitude $=253 \mathrm{E}$

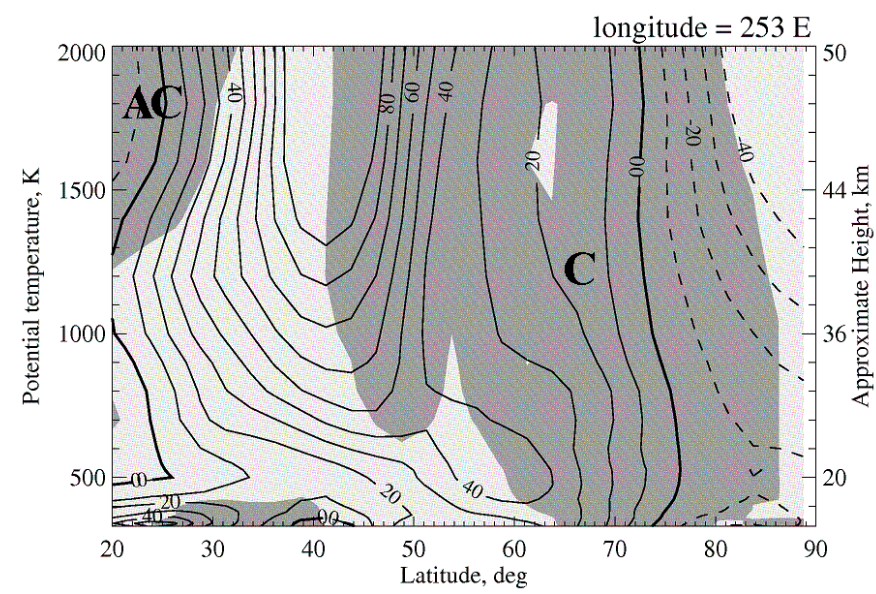

February 25, 2005
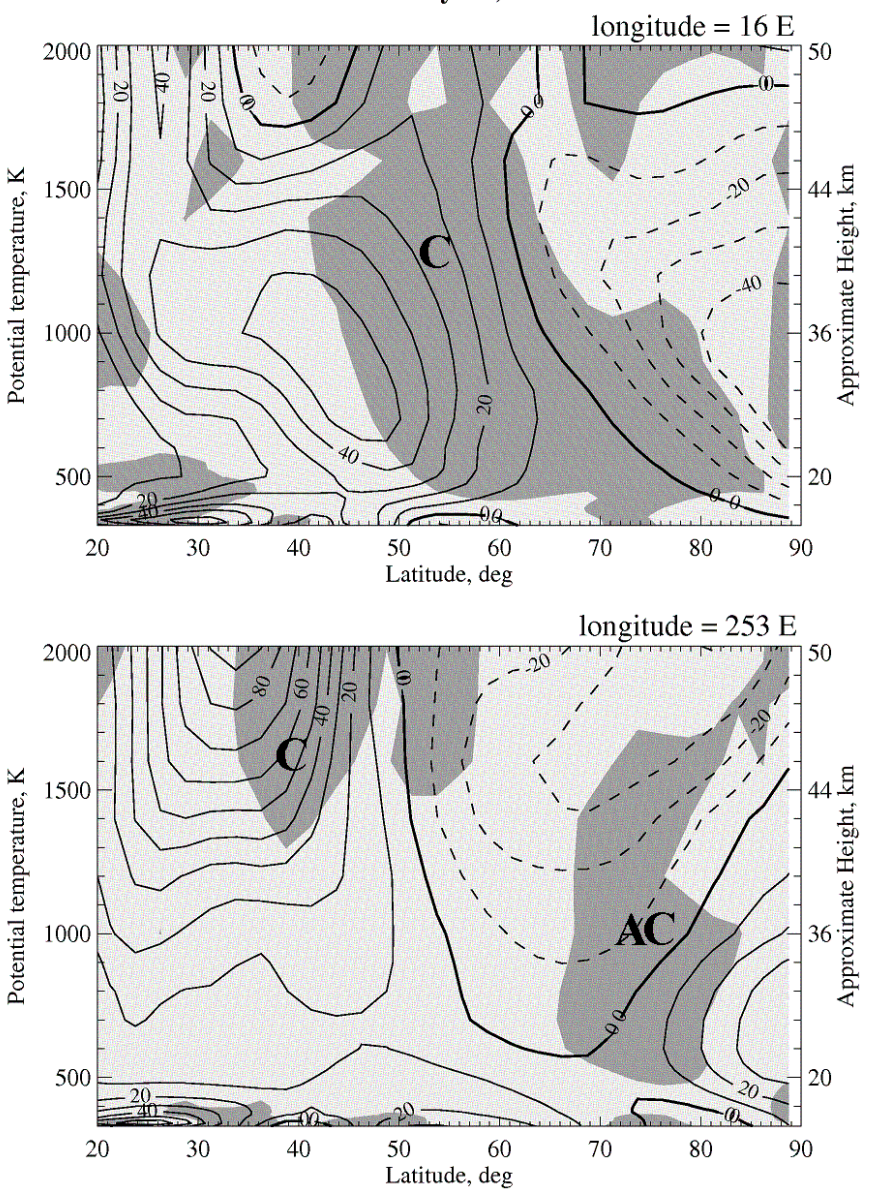

Fig. 3. Zonal winds from low to high latitudes at the chosen Canada-US $\left(253^{\circ} \pm 12^{\circ} \mathrm{E}\right)$ and Scandinavia-Europe $\left(16^{\circ} \pm 12.5^{\circ} \mathrm{E}\right)$ sectors: the two most disturbed intervals of the winter, centred on 1 and 25 February, are shown. Westerly winds are positive and therefore out of the plane of the page. The darker hatching/grey is for the negative values of the Q-diagnostic, where solid rotation dominates; cyclonic $\mathrm{C}$ and anti-cyclonic AC regions are indicated. The hemispheric edges of the polar cyclonic vortex are very close to the southern boundaries of the $Q<0$ cyclonic areas, and the hemispheric edge of the anticyclone is also close to the southern boundary of $Q<0$. Data from MetO have been used.

extending in longitude from Scandinavia-eastern Europe to the western Atlantic. The pole was outside the vortex, whose southern edge reached quite low latitudes $\left(45^{\circ} \mathrm{N}\right)$. As shown in $\mathrm{C} 07$ the SPW 1 increased in size at the time of greatest temperature disturbance for winter 2004/2005. For the upper stratosphere-stratopause the polar vortex and its edge were in the $253^{\circ} \mathrm{E}$ sector. These disparate locations for the cyclonic vortex and its edge in the two sectors are associated with twisting of the polar vortex with height (C07, Fig. 4). Activity associated with planetary and gravity waves will be affected regionally during these strong changes in the direction and strength of the background stratospheric winds. Chemical distributions will also be modified.

\section{Chemical distributions over Canada-US and Scandinavian-Europe}

Aura-MLS provides measurements of key chemicals $\left(\mathrm{N}_{2} \mathrm{O}\right.$, $\mathrm{ClO}, \mathrm{HCl}, \mathrm{O}_{3}, \mathrm{H}_{2} \mathrm{O}, \mathrm{HN} \mathrm{O}_{3}$ ) associated with the travails of ozone, $\mathrm{O}_{3}$, in the various characterizations of the polar vortex of winter 2004/2005. Nitrous oxide, $\mathrm{N}_{2} \mathrm{O}$, is a long-lived gas with its source in the lower troposphere, which can be used as an indicator of vertical motions and also the general position and shape of the vortex (Salby, 1996). In the stratosphere, photolysis leads to the formation of NO, which is a catalyst for $\mathrm{O}_{3}$ destruction. Reactive chlorine is produced by heterogeneous processes that occur with polar stratospheric clouds (PSC), whose formation is favoured in the low temperatures of the polar night where the polar vortex is also usually located. The reservoir species, $\mathrm{HCl}$ and $\mathrm{ClONO}_{2}$, the latter formed by way of chlorine monoxide $(\mathrm{ClO})$, are most 


\section{Canada-USA $\left(253^{\circ} \mathrm{E}\right)$}

\section{December 25, 2004}
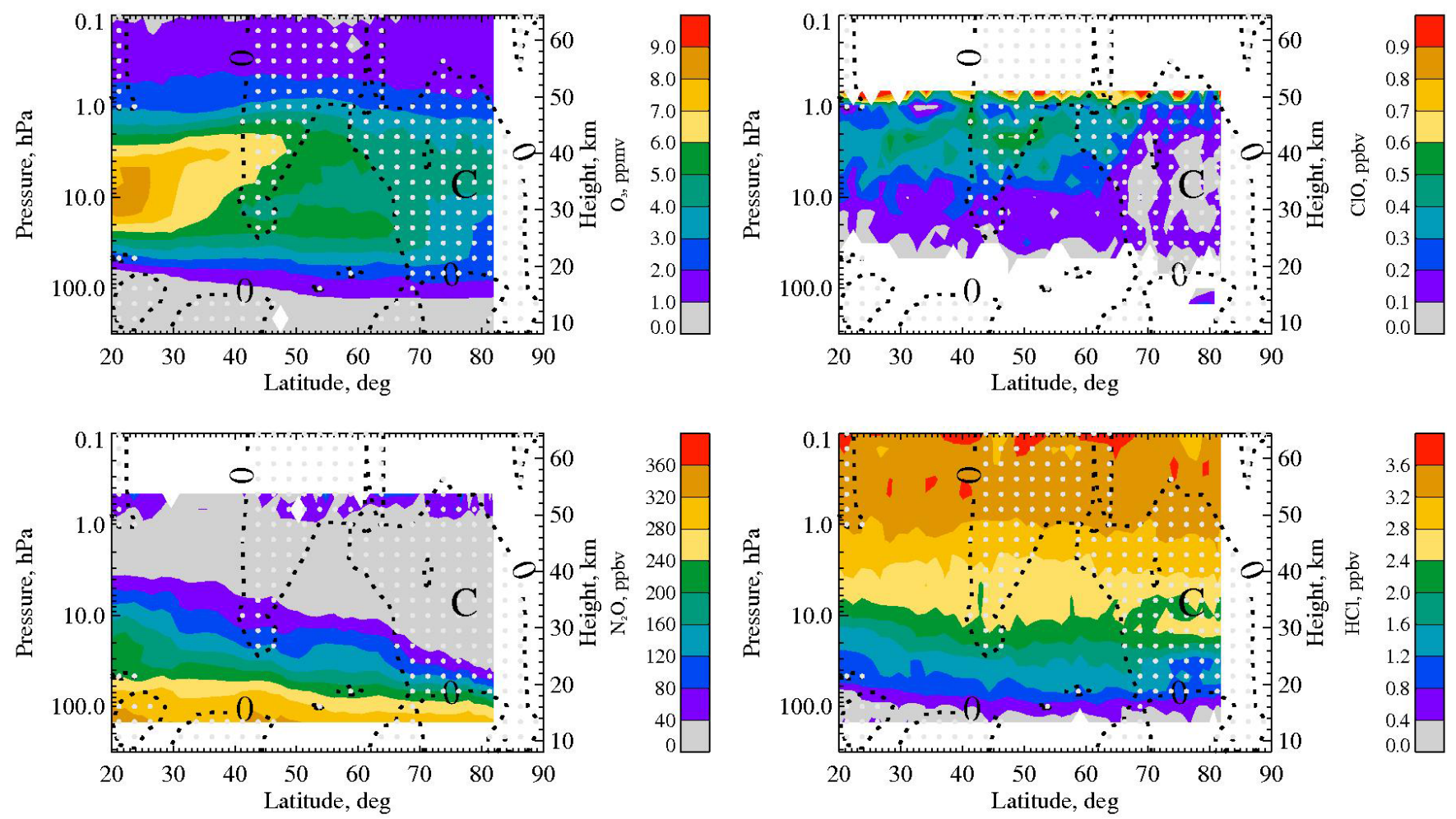

Fig. 4. Contour plots for mixing ratios of four chemicals (Aura MLS) are shown for 25 December, at the chosen longitudinal sector through Saskatoon-Platteville $\left(253 \pm 12.5^{\circ}\right.$ E). Regions of negative Q-diagnostic are dotted in white, with their edges dotted in black. The main cyclonic and anticyclonic regions are marked with the letters $\mathrm{C}$ and $\mathrm{AC}$. The hemispheric polar vortex edges are close to the southern boundaries of the major cyclonic regions: please see text for any related discussion.

numerous during quiet polar conditions. However reactions on surfaces of PSC lead to $\mathrm{Cl}_{2}$ and $\mathrm{HOCl}$ that are easily photolyzed in the spring, or within air-parcels experiencing long excursions to lower latitudes. These latter occur when the vortex is strongly elongated and furthermore displaced from the pole. $\mathrm{ClO}$ will then be the dominant chlorine species. Nitric acid, $\mathrm{HNO}_{3}$, which is also formed in the above PSCreactions, can precipitate out of atmospheric layers/regions as the PSC particles descend (denitrification). Alternatively, evaporation of the PSC at higher temperature leads to $\mathrm{HNO}_{3}$ release, and photolysis to $\mathrm{NO}_{2}$ eventually leads to reformation of the reservoir species $\mathrm{ClONO}_{2}$. Typically $\mathrm{HCl}$ will also become prevalent. $\mathrm{H}_{2} \mathrm{O}$ and $\mathrm{OH}$ are involved as the PSC form and possibly will precipitate out of the air mass; while $\mathrm{H}_{2} \mathrm{O}$ and $\mathrm{ClONO}_{2}$ provide $\mathrm{HOCl}$, which hydrolyzes to $\mathrm{OH}$ and $\mathrm{Cl}$. We shall include figures with $\mathrm{O}_{3}, \mathrm{~N}_{2} \mathrm{O}, \mathrm{ClO}$ and $\mathrm{HCl}$ but refer to other species when appropriate.

The height versus latitude contours for the four chemicals are shown in Fig. 4 for 25 December at $253^{\circ} \pm 12.5^{\circ} \mathrm{E}$ (Saskatoon in west central-Canada). Negative values of the
Q-diagnostic are shown by dots (dashed at the zero $Q$ value). $\mathrm{A}$ capital $\mathrm{C}$ and $\mathrm{AC}$ are added to the major areas of rotational flow in this and the subsequent two figures. We prefer to show the $Q<0$ areas in this fashion, as their areas indicate the latitudinal extent of the vortex in the sector being examined. Also, our inspection of the hemispheric polar vortex edge for 25 December shows that as expected it follows the southward edge $\left(\sim 65^{\circ} \mathrm{N}\right)$ of the cyclonic area very closely up to $\sim 35 \mathrm{~km}$ (Fig. 4), and then moves southward to $\sim 40^{\circ} \mathrm{N}$ for the upper heights of the figure, as demanded by the negative $Q$ area there. Thus at these heights a region of wind shear was imbedded within the vortex. Otherwise the vortex was well defined up to $40-50 \mathrm{~km}$ and centered almost over the pole. Three day intervals are used for this and subsequent figures of similar design, and the MLS-value at a particular latitude (bin) was found by averaging all measurements within half a track spacing (viz., within 12.5 degrees) of the selected longitude. There is no smoothing applied in latitude. 
Ozone mixing ratios, $r\left(\mathrm{O}_{3}\right)$, above $40 \mathrm{hPa}$ decrease from high mid-latitude values (6-8 ppmv) by $\sim 30 \%$ inside the vortex over Canada and also over Scandinavia (not shown). This is not a loss of $\mathrm{O}_{3}$, but shows that the $\mathrm{O}_{3}$-rich air of lower latitudes is not entering the vortex. This natural decrease in mixing ratio within the early winter vortex (Kent at al., 1985; Choi et al., 2002; Manney et al., 1994), when it is simply cold and stable but no chemical losses are occurring (Salby and Callaghan, 2006, 2007), is still not appreciated by some atmospheric scientists who are not close to the field of dynamics and chemistry. Over West CentralCanada (Fig. 4) and Scandinavia the mixing ratio of $\mathrm{N}_{2} \mathrm{O}$ decreases with height and latitude, consistent with its low altitude source and eventually descending air in the vortex. There is less $\mathrm{ClO}$ inside the vortex at both locations, consistent with no solar radiation and hence no photolysis; and $\mathrm{HCl}$ as a reservoir species shows little change across the vortex boundary. Cross-sections for the Atlantic and Alaskan sectors are also similar to Fig. 4. Although there was a significant vortex adjustment near 1 January (Sect. 3; and C07, their Fig. 4), the cross-sections for $16^{\circ}$ and $253^{\circ}$ E showed insignificant chemical changes.

Moving to the warming events near 1 February and 25 February, we show cross-sections for Scandinavia-Europe on both dates (Fig. 5), since the vortex analysis in C07 shows that the $16^{\circ} \pm 12.5^{\circ} \mathrm{E}$ height-latitude sector contained a significant part of the cyclonic vortex for both events. As noted in connection with Fig. 3 in Sect. 4, the southern boundaries of the cyclonic areas are very close to the edges of the hemispherically defined polar vortices. The latitudinal extent of the cyclonic areas for both February events increased since 25 December. The vortex was symmetrical on December 25, so that comparisons with the vortex and chemicals within the sector at $253^{\circ} \mathrm{E}$ (Fig. 4) are appropriate. (Plots for the $16^{\circ} \mathrm{E}$ sector were removed from Fig. 4 to minimize the total size of figures in this paper.) There is even less $\mathrm{N}_{2} \mathrm{O}$ on the two February-dates near $30 \mathrm{hPa}$, consistent with stronger downward motion. There is more $\mathrm{ClO}$ above $\sim 10 \mathrm{hPa}$ and $>65^{\circ} \mathrm{N}$ on 1 and 25 February than on 25 December near $10 \mathrm{hPa}$. Heterogeneous chemistry is not expected there, and air motions (horizontal and vertical) and redistribution of constituents within the vortex have likely occurred. Near $40 \mathrm{hPa} / 20 \mathrm{~km}$ and $70^{\circ}$ a 10 -fold increase is noted on 1 February, and broadened to $50-80^{\circ}$ by 25 February. A matching decrease in $\mathrm{HCl}$ occurred below $20 \mathrm{hPa}$. The loss of a chlorine reservoir and growth of $\mathrm{ClO}$, which is consistent with $\mathrm{O}_{3}$ destruction via heterogeneous chemistry, is consistent with strong $\mathrm{O}_{3}$ losses. Indeed Fig. 5 shows decreases of $\mathrm{O}_{3}$ in corresponding places within the vortex and near $\sim 40 \mathrm{hPa}$ on 1 February and especially 25 February. On the latter date $\mathrm{O}_{3}$ decreases relative to 1 February are also evident above $10 \mathrm{hPa}$, as the blue contours have moved downward, possibly related to warmer temperatures (Fig. 1) or related vertical motions within the vortex. Cross-sections examined for the longitudes as far west from $16^{\circ} \mathrm{E}$ as the Atlantic region show similar patterns of chemical-change.

The chemical changes occurring in February are even more clearly shown in "difference" contour plots between the two February events and the constituents on 11 January. On 11 January the vortex was relatively undisturbed and very similar to that of 25 December. To provide both temporal and spatial differences for the two longitudinal sectors to the readers of this section, it was decided to show the $16^{\circ} \mathrm{E}$ and $253^{\circ} \mathrm{E}$ regional sectors on the same figures (Fig. 7, 1 February; Fig. 8, 25 February). From the top sections of Figs. 7 and 8 , the temporal patterns of change over Scandinavia-Europe on 1 and 25 February are quite similar. However, the reductions in $\mathrm{O}_{3}$ are greater at the end of February, as are the areas affected. Figures 5, 7 and 8 show that substantial decreases/losses in $\mathrm{O}_{3}$ had occurred in the Scandinavia-Europe sector during February (from day 1 to day 25), as other studies discussed in the Introduction have demonstrated with alternative methods. Figures 7 and 8 will be referred to again as required.

We now move to Fig. 6, where Canada-US cross-sections are shown for 1 and 25 February; this is the complementary plot to Fig. 5. On the first date, west central-Canada $\left(253^{\circ} \mathrm{E}\right)$ was still in the vortex, although the vortex was elongated and had moved across the pole to lower Canadian latitudes (Fig. 3). As noted earlier in Sect. 4, the southern boundary of the cyclonic region was very close to the edge of the hemispheric polar vortex. Upon simple inspection the Canadian contours for the four chemicals appear similar to those for Scandinavia (Fig. 5). However the longitudinal variations are quite substantial as seen in the time-difference plots Fig. 7. There is more $\mathrm{ClO}$ (yellowish green contours) at middle to high latitudes near $10 \mathrm{hPa}$ over Canada. Also, as well as decreases and probable losses of $\mathrm{O}_{3}$ over the high mid-latitudes $\left(\sim 65^{\circ} \mathrm{N}\right)$ of Canada where $\mathrm{ClO}$ has increased $(\leq 50 \mathrm{hPa})$, the $\mathrm{O}_{3}$ decreases (from 11 January) near $10 \mathrm{hPa}$ are larger and at lower latitudes $\left(30-50^{\circ}\right)$ than those over Scandinavia. There, increases are evident. Also at $16^{\circ} \mathrm{E}$, changes in the $\mathrm{N}_{2} \mathrm{O}$ time-differences (11 January to 1 February) are significantly different, with relative descent indicated at $50-60^{\circ}$, matching with the segment (green) of $\mathrm{O}_{3}$ increase. Meanwhile ascent (positive green-yellow contours) is indicated over $253^{\circ} \mathrm{E}$, along with $\mathrm{O}_{3}$ decrease. Most of these changes in the sign of the $\mathrm{N}_{2} \mathrm{O}$ differences are related to the changing positions of the vortex and its edge (the Q-diagnostic plots were assessed but are not shown). Alternate possibilities are that at the lower latitudes the air-parcels will have been subjected to more solar radiation and photolysis, which will have led to more $\mathrm{O}_{3}$-loss through PSC or homogeneous chemistry.

Finally we consider the Canada-US location on 25 February (bottom of Fig. 6) and also the variations between longitudinal locations in the time-difference plots of Fig. 8. The hemispheric edges of the AC and C (actually the upper altitude polar vortex) as determined by the Q-diagnostic are very close to the southern edges of the $Q<0$ areas in Fig. 6 . This was previously noted in Sect. 4 in connection with 


\section{Scandinavia-Europe $\left(16^{\circ} \mathrm{E}\right)$}

February 1, 2005
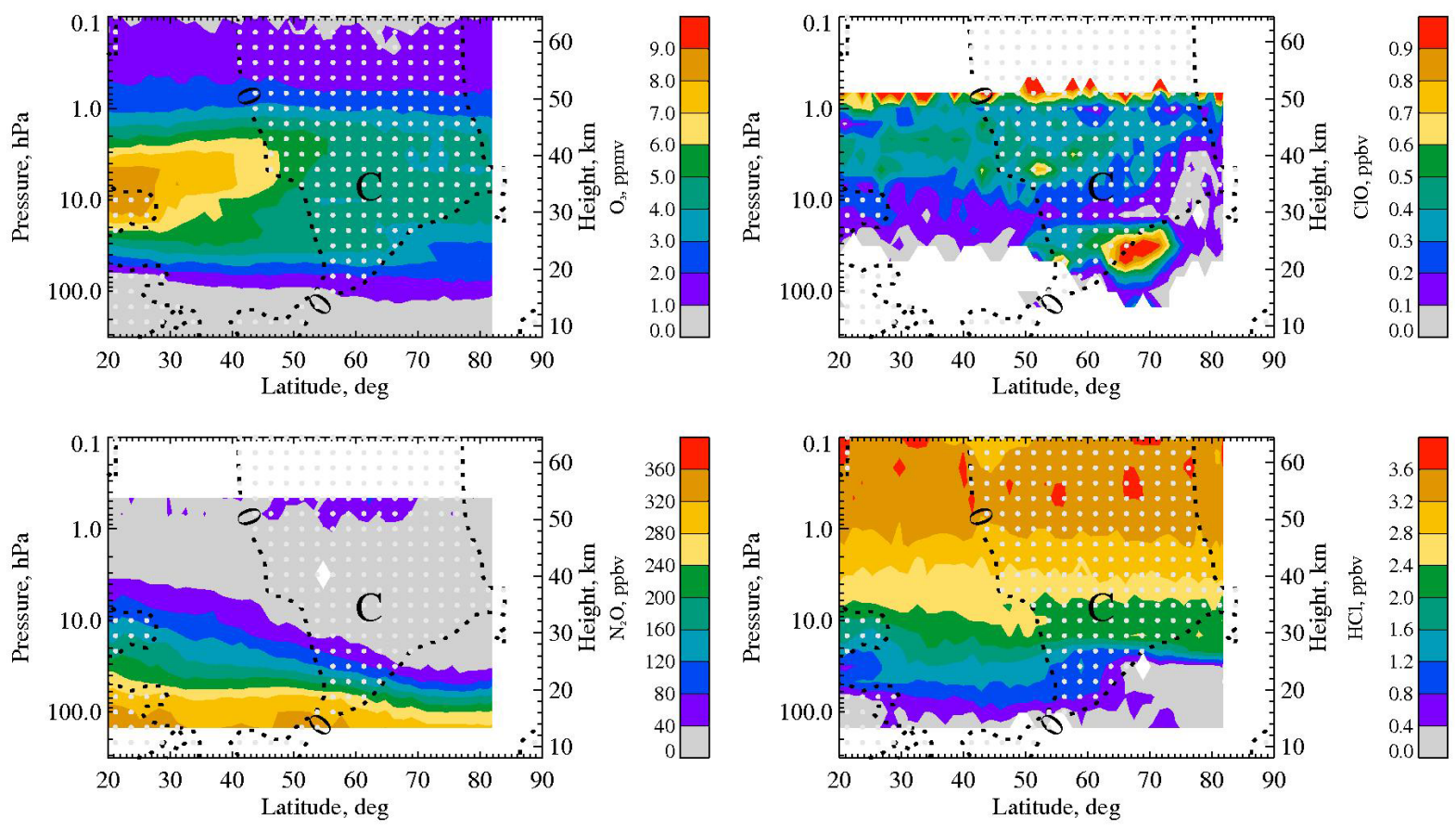

February 25, 2005
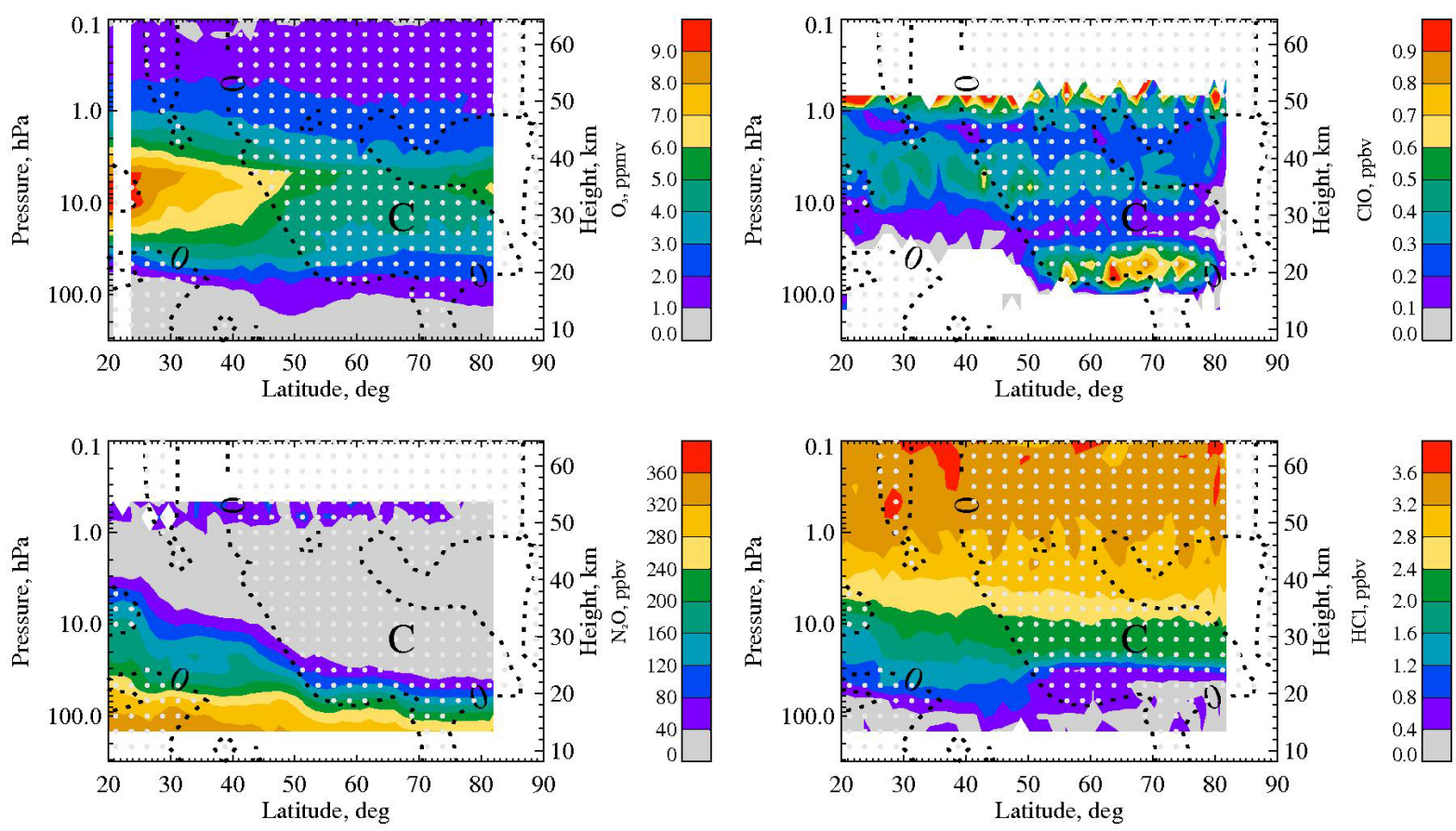

Fig. 5. Contour plots for mixing ratios of four chemicals (Aura MLS) are shown for 1 and 25 February, at the chosen longitudinal sector through Svalbard-Tromso-Collm $\left(16 \pm 12.5^{\circ} \mathrm{E}\right)$. Otherwise details are as in Fig. 4. 


\section{Canada-USA $\left(253^{\circ} \mathrm{E}\right)$}

\section{February 1, 2005}
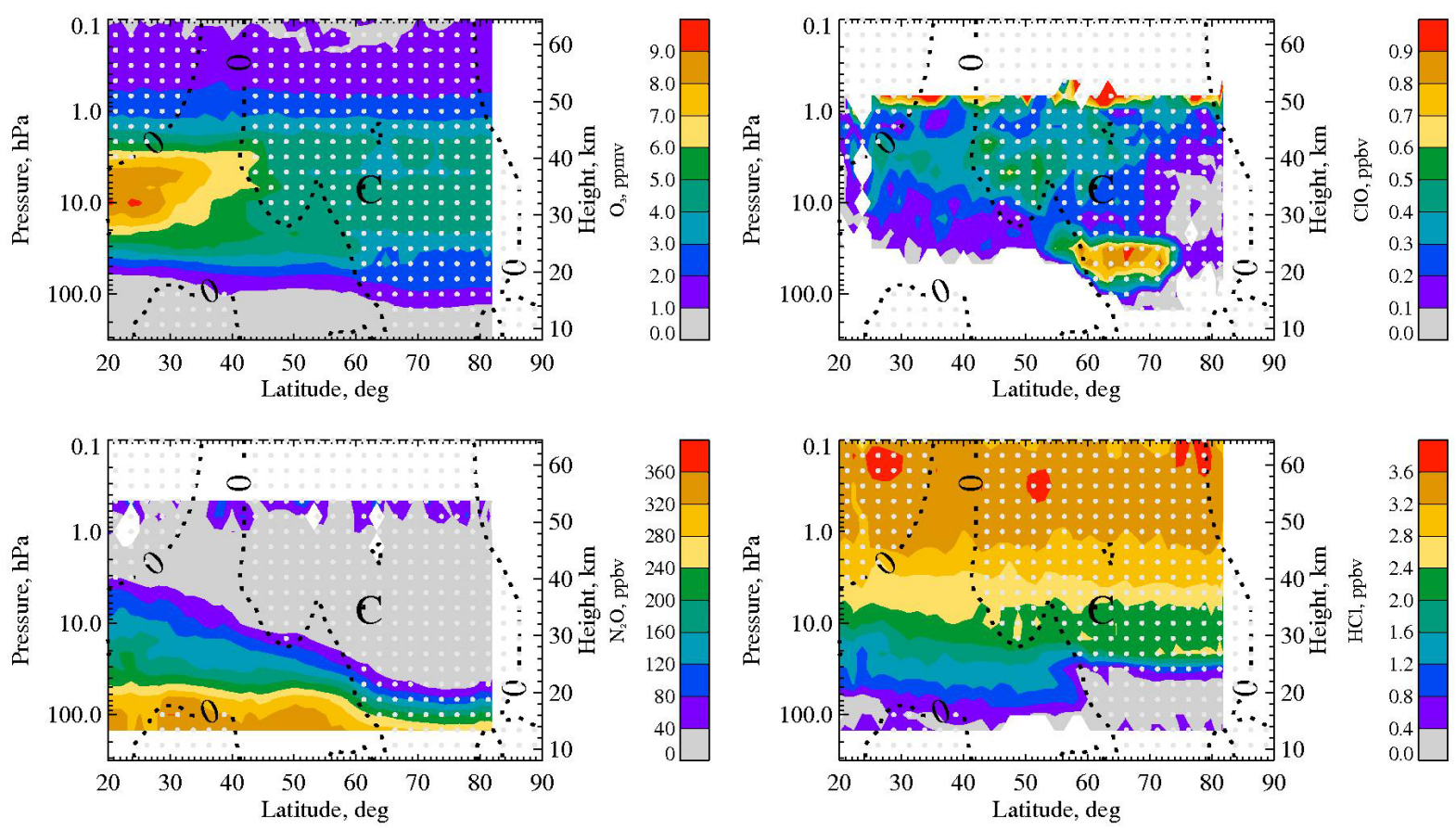

February 25, 2005
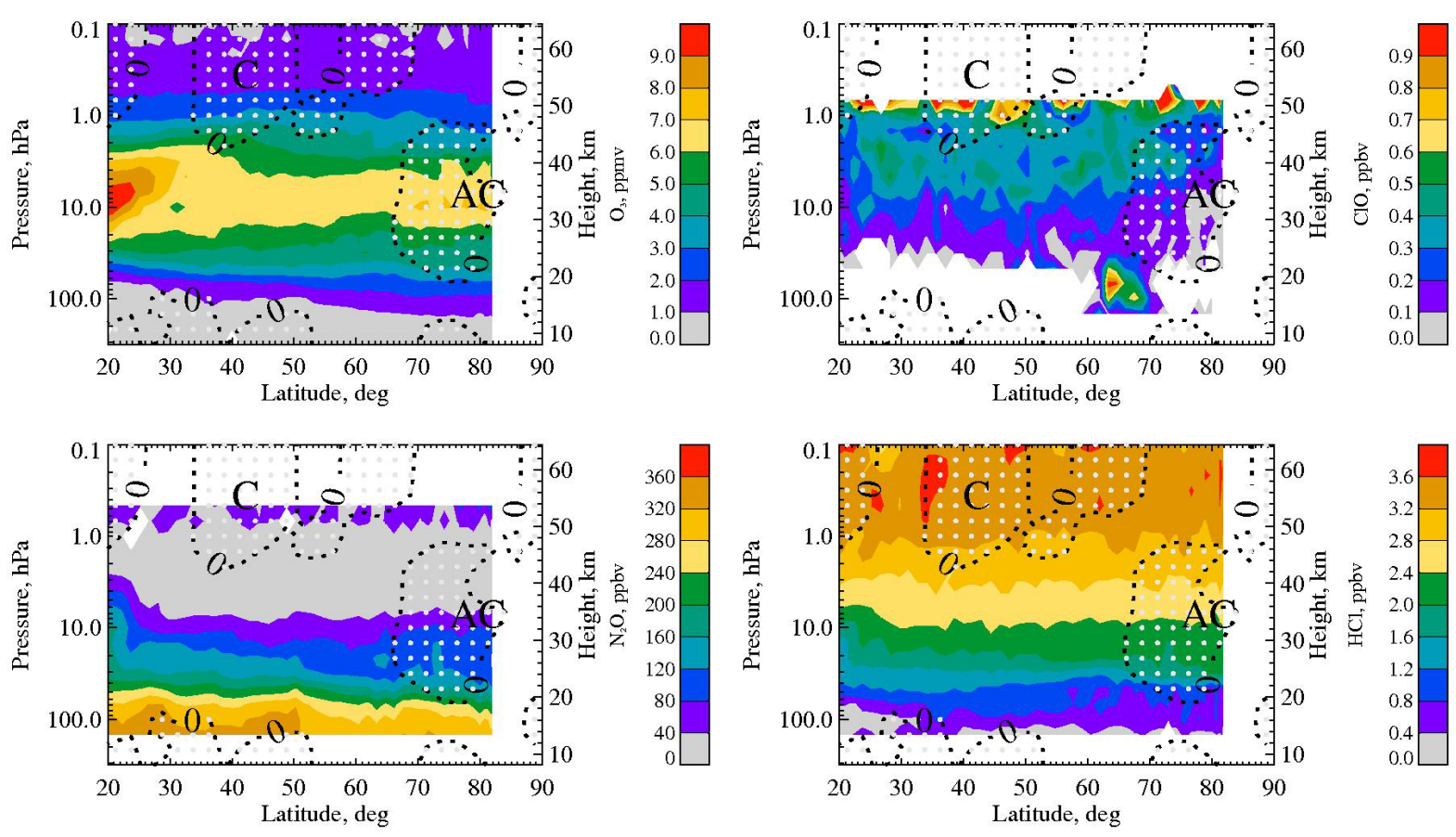

Fig. 6. Contour plots for mixing ratios of four chemicals (Aura MLS) are shown for 1 and 25 February, at the chosen longitudinal sector through Saskatoon-Platteville $\left(253 \pm 12.5^{\circ} \mathrm{E}\right)$. Otherwise details are as in Fig. 4 . The hemispheric vortex edges are close to the southern boundaries of the major anticyclonic and cyclonic regions: please see text for any related discussion. 


\section{February 1 - January 11, 2005}

\section{Scandinavia-Europe $\left(16^{\circ} \mathrm{E}\right)$}
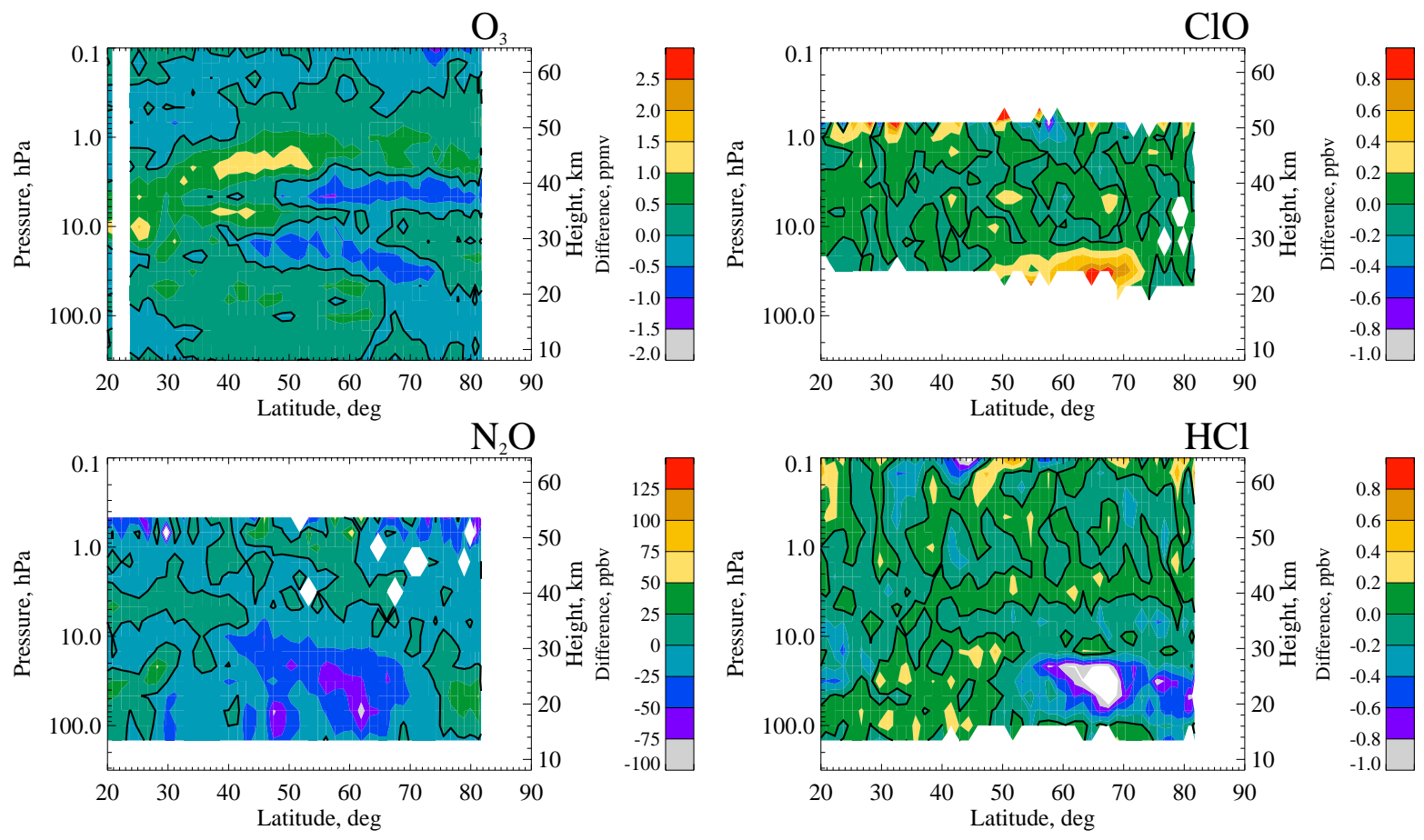

Canada-US $\left(253^{\circ} \mathrm{E}\right)$
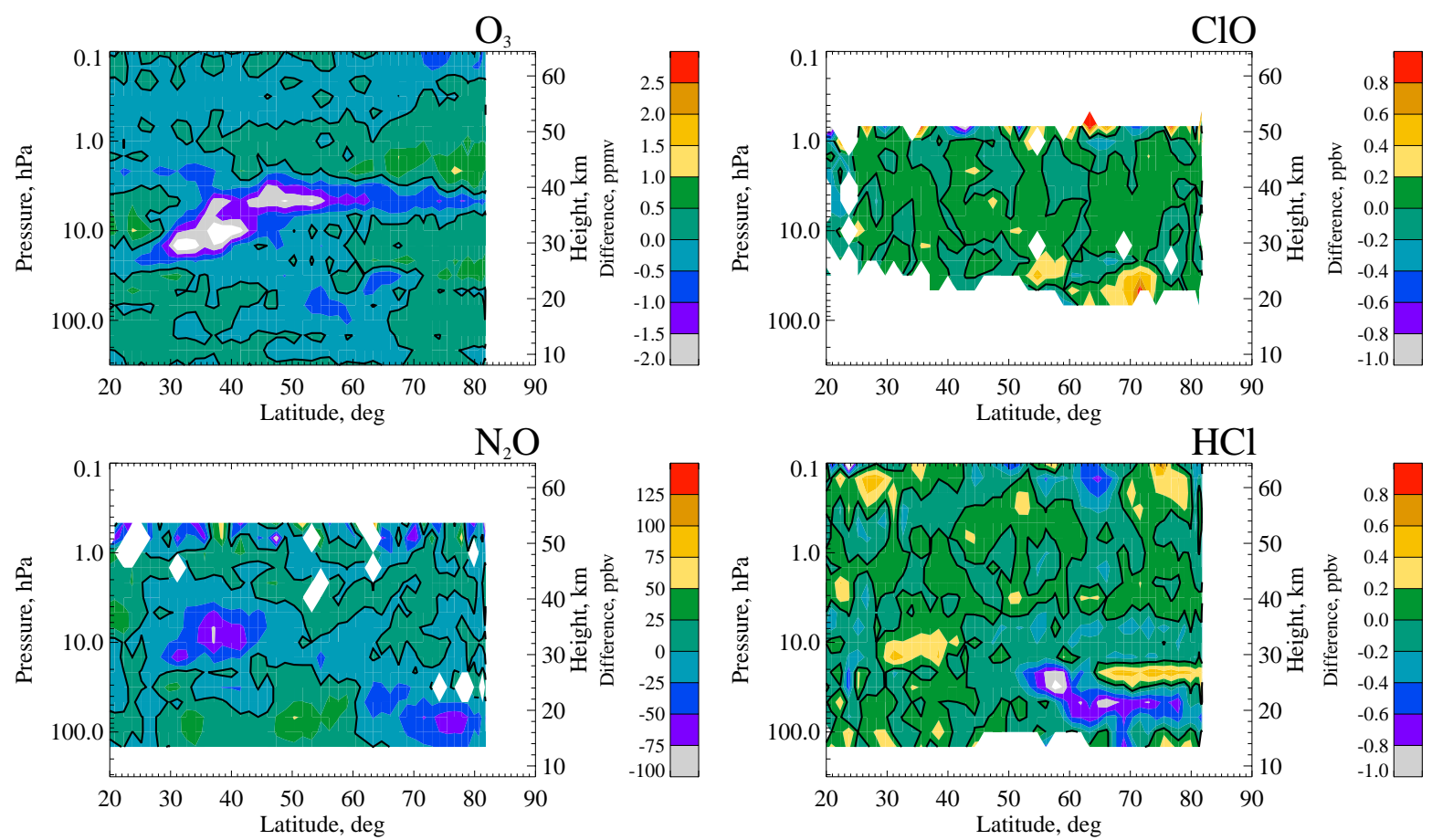

Fig. 7. Contour plots for the temporal differences (1 February minus 11 January) in mixing ratios of four chemicals (Aura MLS), at the chosen longitudinal sectors through Svalbard-Tromso-Collm $\left(16^{\circ} \pm 12.5^{\circ} \mathrm{E}\right)$ and Saskatoon-Platteville $\left(253 \pm 12.5^{\circ} \mathrm{E}\right)$. 
February 25 - January, 11

Scandinavia-Europe $\left(16^{\circ} \mathrm{E}\right)$
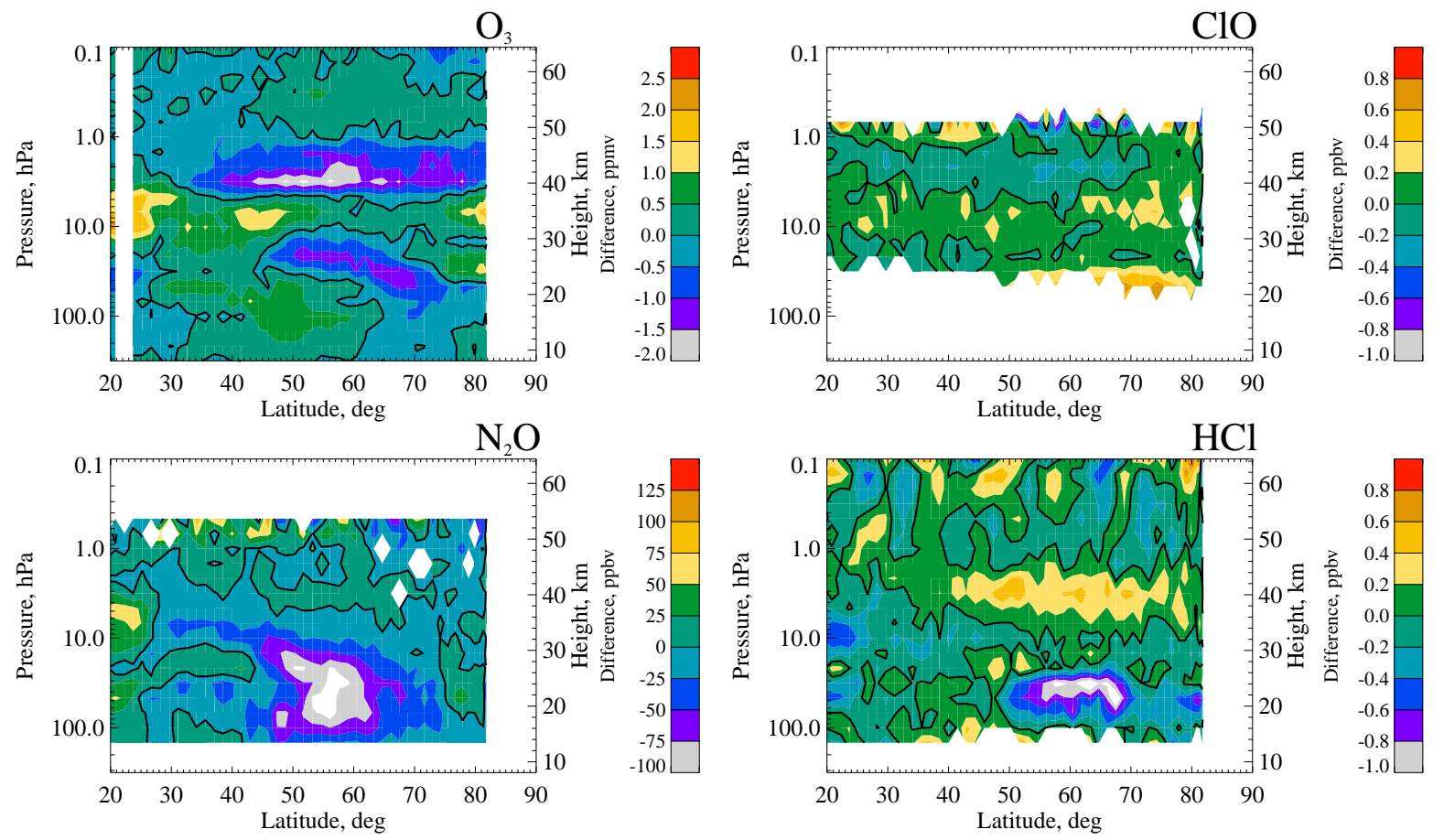

\section{Canada-US $\left(253^{\circ} \mathrm{E}\right)$}
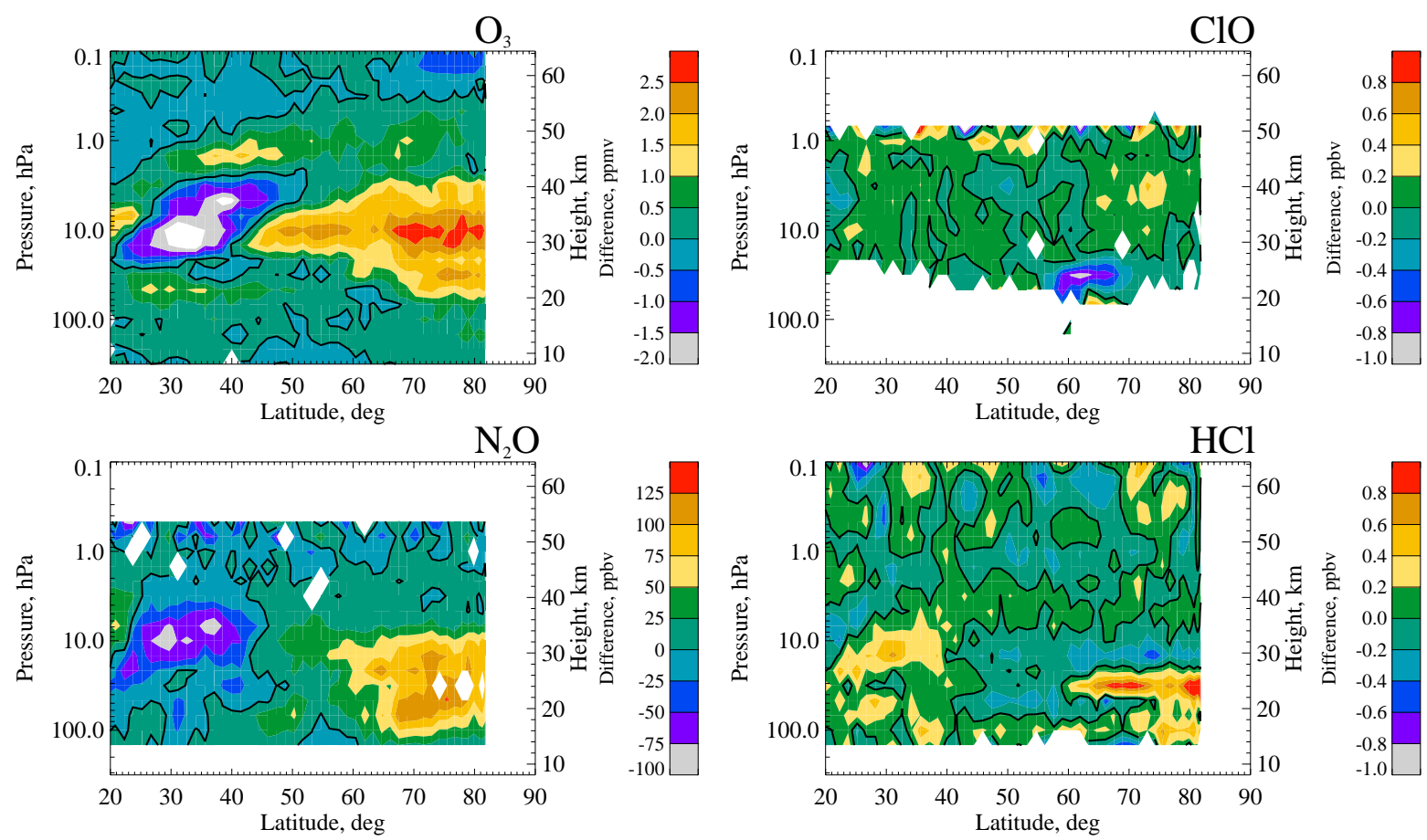

Fig. 8. Contour plots for the temporal differences (25 February minus 11 January) in mixing ratios of four chemicals (Aura MLS), at the chosen longitudinal sectors through Svalbard-Tromso-Collm $\left(16^{\circ} \pm 12.5^{\circ} \mathrm{E}\right)$ and Saskatoon-Platteville $\left(253 \pm 12.5^{\circ} \mathrm{E}\right)$. 
Fig. 3. Contrasts between 1 and 25 February in Fig. 6 are dramatic, especially in comparison with the cross-sections for $16^{\circ}$ (Fig. 5). The presence of the stratospheric warming in the Pacific-Western Canada (PWC) sector is now in full effect and each chemical's contour plots are strikingly different on these two days. The $\mathrm{N}_{2} \mathrm{O}$ contours for $25 \mathrm{Febru}-$ ary are greatly elevated at higher latitudes indicating relative ascent compared to 1 February and to both February dates for Scandinavia-Europe. The area of enhanced $\mathrm{ClO}\left(65^{\circ} \mathrm{N}\right.$, $100 \mathrm{hPa}$ ) has decreased with time, the $\mathrm{HCl}$ values have increased, and near $10 \mathrm{hPa}$ the $\mathrm{O}_{3}$ mixing ratios are high right through to the highest polar latitude $\left(82^{\circ} \mathrm{N}\right)$. This pattern for February extended at least to Alaska at $195^{\circ} \mathrm{E}$.

Returning to the time-difference plots of Fig. 8 for 25 February, they clearly show the ClO/HCL decreases/increases near $40 \mathrm{hPa}$ over Canada, which are reversed from Scandinavia. The positions of the decreased and increased $\mathrm{N}_{2} \mathrm{O}$ contour-values at heights below $\sim 40 \mathrm{~km}$ match the Canadian cyclonic winds at latitudes south of $50^{\circ} \mathrm{N}$ and anticyclonic winds poleward of there (Fig. 3), with inferred downward and upward motions, respectively. Almost the entire region from $20-82^{\circ} \mathrm{N}$ and $100-1 \mathrm{hPa}$ now shows increases in $\mathrm{O}_{3}$, especially poleward of $40^{\circ}$ near $10 \mathrm{hPa}$. These are evidently due to advection of $\mathrm{O}_{3}$-rich air from low latitudes, and the movement of the polar vortex edge (at low-middle stratospheric altitudes) to either very high polar latitudes or to the Scandinavia-Europe sector; this is for longitudes ranging from western Canada to Alaska. The lower $r\left(\mathrm{O}_{3}\right)$ values at low latitudes and $10 \mathrm{hPa}$ in Fig. 8 are associated either with the complementary advection of that ozone toward the pole, or due to redistribution associated with the new positions of the $\mathrm{AC}$ and $\mathrm{C}$.

Inspection of the vortex and height versus latitude plots for Scandinavia-Europe and Canada-US beyond 25 February revealed generally similar patterns until near 6 March. Ozone mixing ratios did increase modestly at both longitudes, consistent with Manney et al. (2006), whose values for the vortex are described in terms of equivalent latitude. The vortex did not recover a pole-centered cyclonic circulation as existed in late December. For example, on 15 March although the vortex was almost symmetrical about the pole above $800 \mathrm{~K}(\sim 10 \mathrm{hPa})$, the shape below that continued to be strongly elongated. There were continued differences in chemical distributions over Scandinavia and Canada, but vortex ozone losses were minimized because of the early final spring breakdown.

\section{Evolution of the Polar vortex (October-February)}

Often, initiation of vortex studies for a given year has been placed upon temperature increases or perturbations in the zonal mean $10 \mathrm{hPa}$ values at higher latitudes $\sim 60^{\circ} \mathrm{N}$ or $\mathrm{S}$. Such warming events in the lower stratosphere, whether they are major or minor, have effects upon the characteristics of the vortex and the chemicals therein. In Sect. 5 we have shown that even minor warmings such as that of 1 January and 1 February are associated with vortex-elongation and displacement from the pole, and the growth of significant anticyclones in the Aleutian and Russian sectors. These can lead, and in the case of the winter of 2004/2005 have led, to significant longitudinal and latitudinal complexity in chemical distributions and hence to ozone changes and related losses. It is also unfortunately the case that studies continue to be made and papers published that provide scant attention to the characterization of the vortex. In essence the zonal mean temperature or winds receive initial attention, and then some regional effects are assessed e.g. Jimenez et al. (2006). Also the paper by Chshyolkova et al. (2008) on the dynamics and chemistry of the polar vortex for winter 2005/2006 was initiated for two reasons: other papers had excluded the mesospheric radar winds from Saskatoon because they were "inconsistent" with the winds over Europe; and the loss of ozone in that winter was not very large overall, leading to relatively few papers for that year. One of the results of using the effective and quantitatively efficient method of equivalent latitudes for the vortex tends to lead to loss of regional information; the main purpose of such papers may have been to establish with good accuracy the loss of ozone over the winter and spring. Several intervals of 2004/2005 are discussed below, and the materials of Sects. 3-5 including temperatures, winds and chemicals, are shown in useful and powerful hemispheric context using our knowledge of the vortex structure and edge.

\subsection{November-December}

Given that we have already used figures and text that include December data, we provide this short section on the beginnings of the vortex for 2005/2006. The polar vortex started to form in early autumn. During November-December it was displaced off the pole and had a shape of a cone with the area of the vortex decreasing from the upper stratospheric levels down to $\sim 500 \mathrm{~K}(20 \mathrm{~km})$. The displacement of the vortex was toward Eurasia, which happens frequently $(>50 \%)$ according to studies by Harvey et al. (2002) and Karpetchko et al. (2005). There was also indication of Planetary Wave Breaking (PWB) events in the low-to-middle stratosphere. Such events manifest themselves as the large scale irreversible deformations of potential vorticity (PV) contours on isentropic surfaces (McIntyre and Palmer, 1983). Several such events were found during November and December, where there were clear tendencies for PV tongues, originating from high latitudes, to be associated with anticyclones. When planetary waves (PW) break, the cross-stream PV gradient is destroyed, and the possibility of propagation decreases. Such was shown in the model-study by Polvani and Saravanan (2000). The observed breaking of PW in the lower stratosphere is consistent with weaker vertical PW propagation into the middle atmosphere during the 2004/2005 winter. 


\section{Zonal mean zonal wind; November1-December 31}
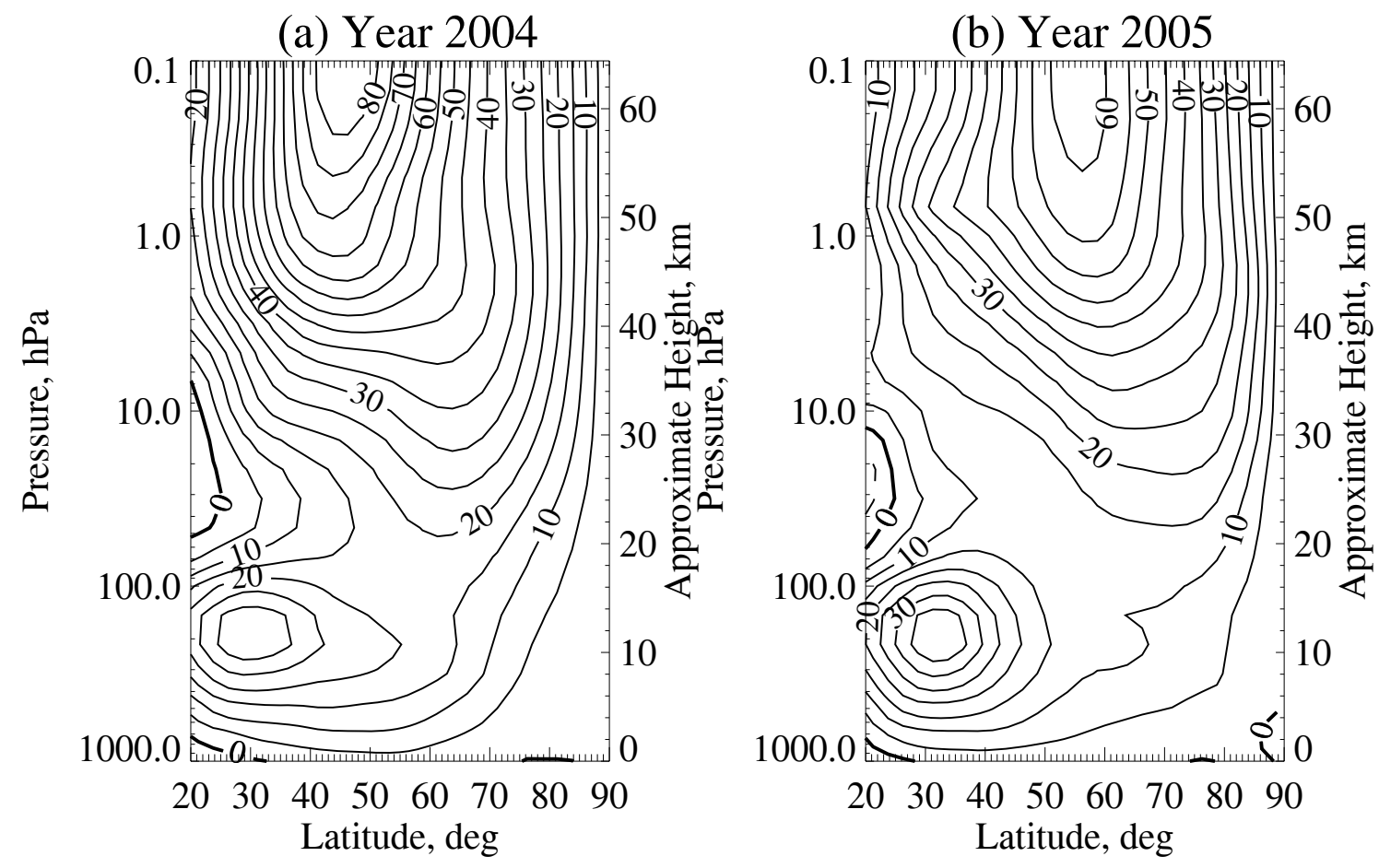

Fig. 9. Contour plots of wind (from MetO) for the November-December months of the winters of 2004/2005 and 2005/2006. The wind-values (positive numbers are westerly) are zonal-means of the zonal winds, in $\mathrm{m} / \mathrm{s}$.

This is in agreement with earlier findings by Chshyolkova et al. (2007) that indicated lower (compared to other years) PW activity at upper stratospheric and mesospheric heights.

According to a statistical study by Abatzoglou and Magnusdottir (2007) using 25 years of ERA-40 reanalysis data, PWB events are associated with unique atmospheric climatologies depending on whether they occur in the upper or lower part of the vortex. Specifically, the zonal-mean zonal wind profiles have features or anomalies associated with those PWB events. Firstly, to compare with their study of early winters (1 November-31 December) with PWB occurring at lower heights, we have constructed wind profiles using contours in a height versus latitude plot for winter 2004/2005 (Fig. 9a). It closely resembles their composite of 7 years with multiple lower stratospheric PWB (their Fig. 3a). Our figure also has strongest winds above $40 \mathrm{hPa}$ near $\sim 40^{\circ} \mathrm{N}$, weaker winds poleward of $60^{\circ} \mathrm{N}$ between 10 and $1 \mathrm{hPa}$, and a weaker tropospheric jet. This favors PWB events in the lower parts of the vortex.

We also show the zonal-mean of the zonal winds for early in the winter season 2005/2006 (Fig. 9b), the winter with the major stratospheric warming in the latter half of January (Keil et al., 2007). The tropospheric jet of NovemberDecember is stronger than the previous year, the polar vortex above $50 \mathrm{hPa}$ is weaker at its core $(0.1 \mathrm{hPa})$ and it is centred further poleward. There is also a poleward tilt of the vortex with decreasing height. Our figure is thus very similar to Fig. 3c of Abatzoglou and Magnusdottir (2007). According to their composite obtained from 10 years, we characterize 2005/2006 as a winter with a weaker vortex and warmer temperatures, which should have been preceded by multiple PWB at the upper stratospheric levels (850-1200 K) in early winter months. We have completed a study of the 2005/2006 winter (Chshyolkova et al., 2008) and PWB at the upper stratospheric levels have been located. Dynamical chemical assessments and comparisons with 2004/2005 are also included in this submitted paper.

These two classifications, demonstrated nicely for years $2004 / 2005$ and 2005/2006, are consistent with the vortex response to the phases of the QBO under conditions of solar minimum activity (Labitzke and Kunze, 2006; Labitzke et al., 2006). For year 2005/2006 the QBO was of "east phase" (meaning easterly equatorial stratospheric winds), leading to warmer mid-winter temperatures associated with the presence of major stratospheric warmings. In contrast, for 2004/2005 the QBO was of "west phase", leading to midwinter colder temperatures associated with the absence of "mid-winter major warmings" or the more usual phrase "major stratospheric warmings". 
Average Aura Ozone Mixing Ratio: 2005 Jan 28-30 (UT). $\Theta=1200 \mathrm{~K}(\sim 38 \mathrm{Km})(3.5-7.7)$
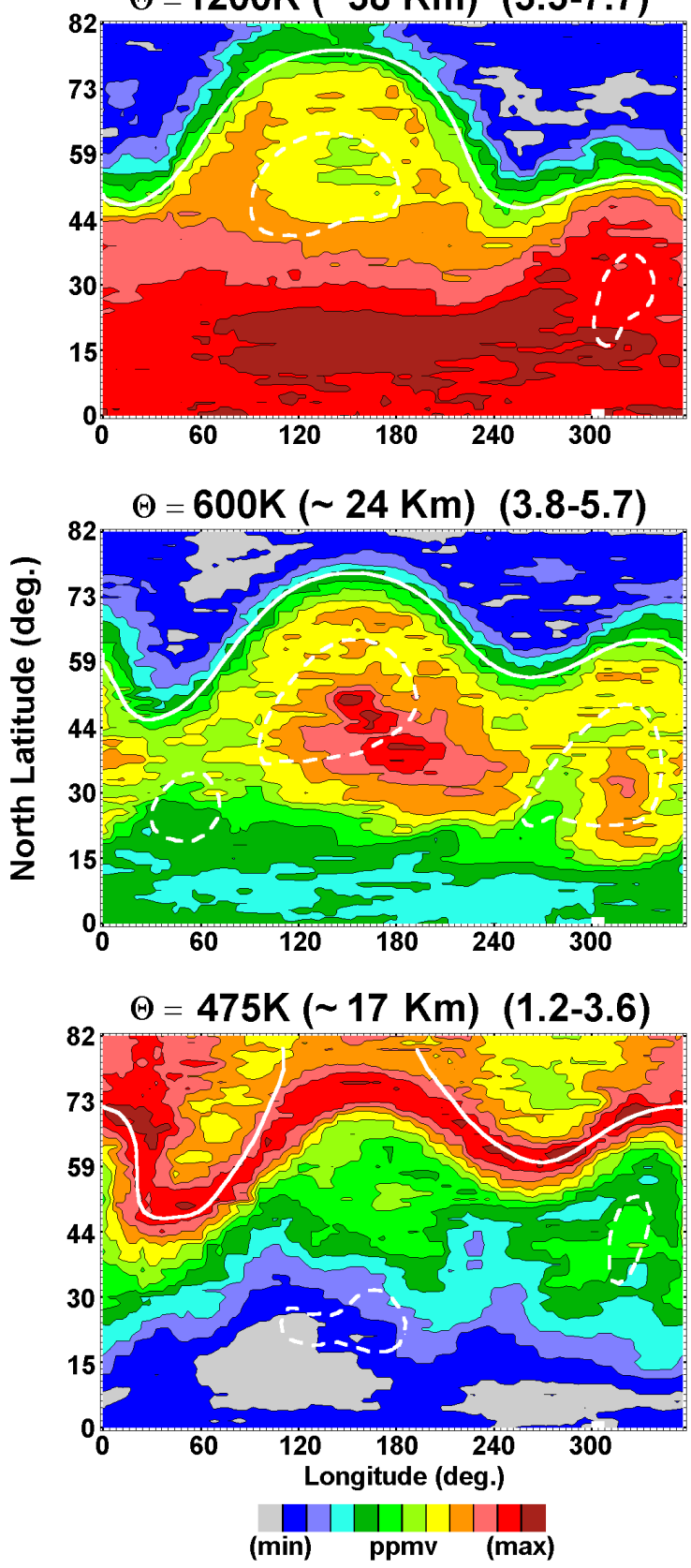

Fig. 10. Polar cylindrical hemispheric contour plots of the 3-day average mixing ratios of ozone (Aura MLS) for three heights. These are for a day (29 January) within the 1 February "warming event" defined in Sect. 3: "the end of a warming trend or "temperature disturbance" (typically $\sim 10$ days in duration) as indicated by zonal mean MetO temperatures at $60-70^{\circ} \mathrm{N}$ and $10 \mathrm{hPa}$ ". The edge of the polar vortex as determined by the Q-diagnostic using MetO (data assimilation model) is shown with a solid white line (see text); the edge of the anticyclone is located with a dashed white line.
In fact, the "2004/2005 Arctic winter lower stratosphere was the coldest on record, with potential for polar stratospheric cloud (PSC) formation on more days and over a larger region than in any previously observed Northern Hemisphere (NH) winter" (Manney et al., 2006). Indeed the temperatures and ozone-chemistry shown and discussed in Sects. 3 and 5 are consistent with this statement. Feng et al. (2007) also showed that the development of areas capable of maintaining PSC and the evolution of minimum temperatures below 195 and $190 \mathrm{~K}$ (respectively NAT (nitric acid trihydrate) and ice) increased rapidly after mid-December. Below we focus on the 1 and 25 February warming events and their effect upon ozone losses in the context of the hemispheric polar vortex: the locations of the Canada-US and Scandinavia-Europe sectors continue to be of particular interest.

\subsection{February event}

We begin with a set of longitude-latitude plots of ozone mixing ratio for heights from $475-1200 \mathrm{~K}(\sim 17-38 \mathrm{~km})$, for 3 days centered on 29 January, which is near the start of the event (Fig. 10). In these three plots, and those of similar design used elsewhere in this section, data within half a track spacing of each selected longitude (here stepped by 4 degree) are averaged. There is no averaging over latitude. Because there are large mixing ratio changes with height and we are interested in comparing variations within each plot, each height has its own min-max scale as indicated in the respective titles. Those numbers may be applied to the colour-scale at the bottom of the figure if absolute values are of interest. The min-max scales and colours emphasize the latitudinal variability and hence the vortex influence. Note that the variation with height is strong, such that the largest polar latitude values of mixing ratio (ppmv) occur between 24 and $38 \mathrm{~km} / \sim 600$ and $1200 \mathrm{~K}$, as shown in Figs. 5 and 6.

The first comment is on the vortex characterization provided by the Q-diagnostic (white-line) obtained from MetO data. An edge-band is well defined from 17-21 km (Fig. 10, and the ozone plot of Fig. 11), where an increase of $\mathrm{O}_{3}$ occurs ( $\sim 40 \%$ greater than outside over $10^{\circ}$ of latitude width) with lower values inside (25-50\% lower than the band). This band is due to downward motion of a tongue of $\mathrm{O}_{3}$-rich air. The edge-enhancement of $\mathrm{O}_{3}$ exists for only $\sim 4 \mathrm{~km}$. Below $17 \mathrm{~km}$ there are larger values (factors of more than 2) at high latitudes $\left(45-82^{\circ} \mathrm{N}\right)$ compared to lower $\left(0-45^{\circ} \mathrm{N}\right)$; and for $24 \mathrm{~km}$ and above, there are sharp boundaries due to strong gradients in $\mathrm{O}_{3}$ at the vortex edges, with markedly lower values inside the vortex. The sinusoidal shape of the edge $(\geq 17 \mathrm{~km}$ ) is comprised of wave numbers $n=1$ and 2 (Fig. 2, $\mathrm{C} 07)$, and is a peanut-elliptical shaped structure not centered on the pole on 29 January. Ozone minima at low/high latitudes at heights below/above $\sim 20 \mathrm{~km}$ are consistent with the typical distributions of zonal-mean mixing ratios of ozone for January-February 1979 as shown by Salby (Fig. 1.17, 1996). 


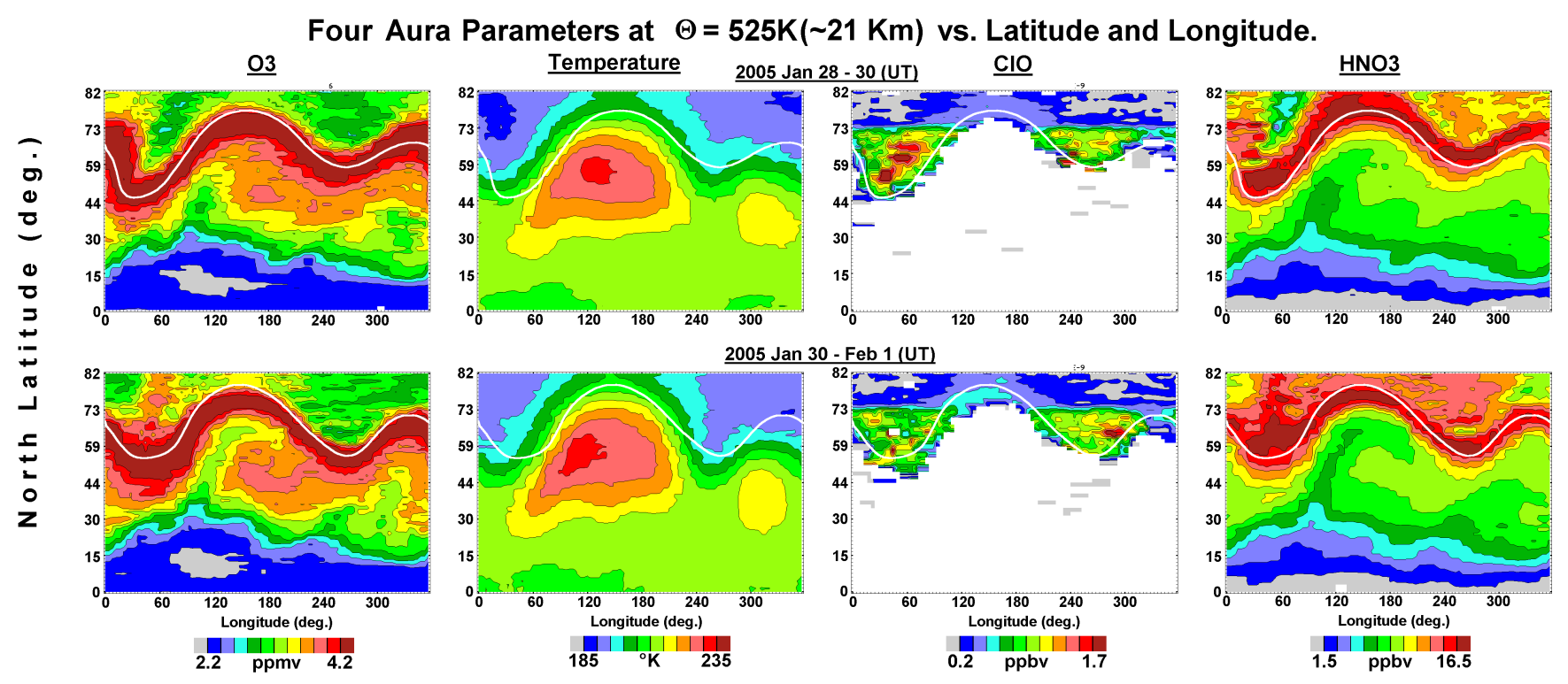

Fig. 11. Polar cylindrical hemispheric contour plots of the 3-day average mixing ratios of ozone, temperature, chlorine monoxide and nitric acid (Aura MLS). These are for two days (29 and 31 January) within the 1 February "warming event" as defined in Sect. 3. The edge of the polar vortex as determined by the Q-diagnostic using MetO (data assimilation model) is shown in white (see text).

At heights of $15-25 \mathrm{~km}$ in the lower stratosphere, the mixing ratio $r\left(\mathrm{O}_{3}\right)$ is a tracer, and in the absence of chemistry, it is dynamically controlled; above $30 \mathrm{~km}$, photochemical influences begin to dominate. However notice that the $r\left(\mathrm{O}_{3}\right)$ still follows the wave structure at $38 \mathrm{~km}$ in Fig. 10 and indeed up to $50 \mathrm{~km}$ (not shown), where the shape of the edge becomes increasingly dominated by the wave $n=1$. The zonal asymmetry thus exists up through to the stratopause. At these upper heights, although the lifetime of the ozone molecule is comparatively small, ozone is continually recreated in those phases of the wave front where the chemical conditions are favorable.

The anticyclone (AC) locations are also added to Fig. 10 as suggested by one of the reviewers (white dashed lines). The dominant AC lies within the Pacific, and some higher values of ozone lie near to the AC regions at $600 \mathrm{~K}(\sim 24 \mathrm{~km})$; lower values of ozone in the $100-200^{\circ} \mathrm{E}$ high latitude sector correspond well with the $\mathrm{AC}$ at $1200 \mathrm{~K}(\sim 38 \mathrm{~km})$ and also $800 \mathrm{~K}$ (not shown). Such low ozone pockets (LOP) had been identified by Manney et al. (1995), and a documentation of all LOPs observed from solar occultation instruments (19912003) has recently been provided by Harvey et al. (2004). These reductions in $r\left(\mathrm{O}_{3}\right)$ are due to containment or separation of air volumes, as also occurs within the cyclonic vortex: air within the high latitude $\mathrm{AC}$ receives less solar radiation, leading to fewer oxygen atoms and hence lower $r\left(\mathrm{O}_{3}\right)$ (Morris et al., 1998).

In Fig. 11 we show latitude versus longitude plots of $\mathrm{O}_{3}$, temperature $T, \mathrm{ClO}$ and $\mathrm{HNO}_{3}$ on 29 and 31 February at $525 \mathrm{~K}(\sim 21 \mathrm{~km})$. The figure demonstrates the changing positions of $\mathrm{O}_{3}$-rich air within the vortex, and also the edge of the vortex. The edge provides strong variations of ozone maxima with latitude and longitude. On 29 January, as the vortex edge near $0^{\circ} \mathrm{E}$ is distorted toward the pole, local maximum values in ozone stretch from $0-40^{\circ} \mathrm{E}$ and $\sim 35-80^{\circ} \mathrm{N}$, while neighboring vortex regions of low $\mathrm{O}_{3}\left(40-60^{\circ} \mathrm{E}\right)$ are accompanied by regions of increased $\mathrm{ClO}$. Two days previously, due to relative motions within the vortex, the region of low $\mathrm{O}_{3}$ and increased $\mathrm{ClO}$ had been $20^{\circ}$ toward the west. By 31 January (Fig. 11) eastward motion of the air within the vortex has brought the feature of higher $\mathrm{O}_{3}$ (the orange contour extends to $82^{\circ} \mathrm{N}$ ) to $\sim 45 / 60^{\circ} \mathrm{E}$ (Eastern Europe), and subsequent unplotted days show the feature reaching $\sim 120^{\circ} \mathrm{E}$ (China). The cells of high (red) $\mathrm{ClO}$ accompany the low $\mathrm{O}_{3}$ regions (green), and temperatures are suitably low (some are plotted, others noted from data-inspection) for PSC formation (185-190 for 24-28 January; 190-195 30+ January). The longitudes $0-90^{\circ} \mathrm{E}$, where the curvature of the vortex is consistent with cyclonic motions (from the Q-diagnostic definition), also have low $\mathrm{ClO}$ values north of $73^{\circ}$. These values of $\mathrm{ClO}$ occur at the lowest temperatures (24-28 January), where $\mathrm{HNO}_{3}$ is also lowest, suggesting increased $\mathrm{ClONO}_{2}$ and some de-nitrification (Jimenez et al., 2006).

The increases in $\mathrm{ClO}$, their positions $\left(0-60^{\circ} \mathrm{E}\right.$ and $240-$ $\left.270^{\circ} \mathrm{E}\right)$ and latitudinal extents are fortuitously consistent with the Canada-US $\left(253^{\circ} \mathrm{E}\right)$ and Scandinavia-Europe $\left(16^{\circ} \mathrm{E}\right)$ plots of Figs. 5-8. These locations were originally chosen in $\mathrm{C} 07$ due to the locations of relatively numerous radars and high latitude observatories in Scandinavia. Such coincidences illustrate how choices of ground-based observational systems, with no attendant knowledge of the positions of the polar vortex, can lead to apparently inexplicable 


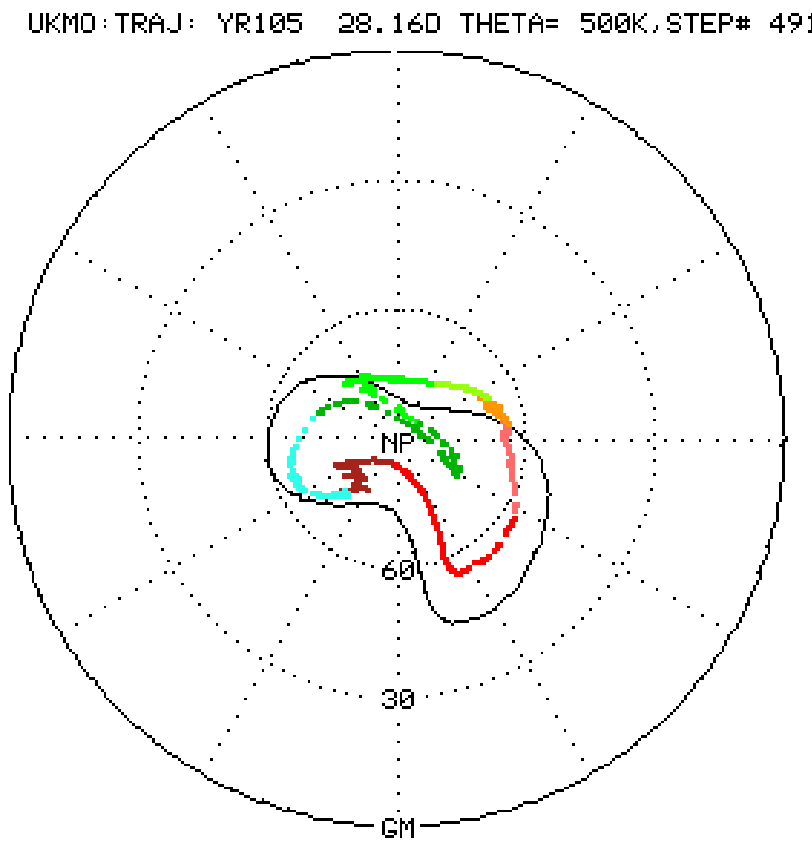

UKMO: TRAJ: YR105 32.06D THETA= 500K, STEP\# 991

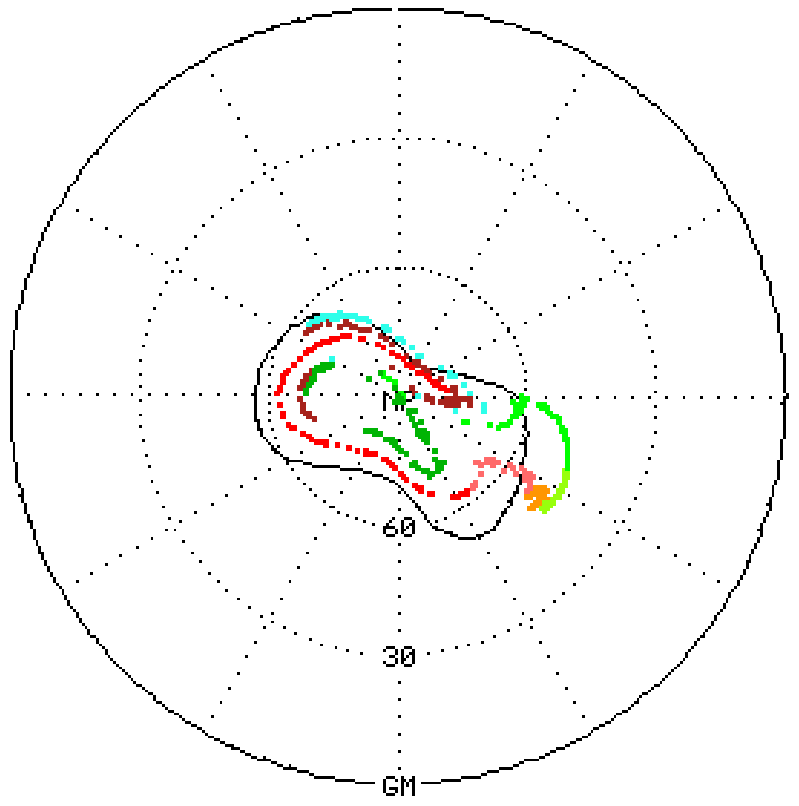

Fig. 12. Trajectory analyses at $500 \mathrm{~K} / 20 \mathrm{~km}$ for two days $(28$ January and 1 February) within the 1 February temperature/vortex event of winter 2004/2005. Air parcels were released at the $70^{\circ} \mathrm{N}$ circle on 24 January: burgundy red at $16^{\circ} \mathrm{E}$ and middle/bright green at $253^{\circ} \mathrm{E}$. The vortex edge (from the Q-diagnostic) is shown by the black contour.

results. In contrast the $\mathrm{HNO}_{3}$ spatial variations shown in Fig. 11 are more complex, and would require regional output from a chemical model for appropriate quantitative explanations. Qualitatively, the maxima in $\mathrm{HNO}_{3}$ on the poleward side of the ozone-rich vortex edge near $180^{\circ} \mathrm{E}$, and also max- ima near $60^{\circ} \mathrm{E}$ where $\mathrm{ClO}$ maximizes, are consistent with heterogeneous chemical reactions involving ozone destruction.

Clearly, knowledge of the position and shape of the vortex are essential for any interpretation of temporal changes in $r\left(\mathrm{O}_{3}\right)$. Otherwise, changes at any high latitude location between 0 and $180^{\circ} \mathrm{E}$ during this 1 February event could be due to movement of the vortex edge in latitude or longitude, or of parcels of gas within the vortex. The shape of the vortex edge, which in Fig. 11 has a sinusoidal variation, is a function of the changing phases and amplitudes of the $n=1$, 2 quasi stationary planetary waves (C07: Fig. 2).

Finally, we discuss some results of a trajectory analysis, which has been described in the Sect. 2. Parcels of air, which are passive tracers of motions, were arrayed in latitude circles at $70^{\circ}$ and $50^{\circ}$ on the $500 \mathrm{~K} / 18 \mathrm{~km}$ surface. Those released at $50^{\circ}$ remained outside the vortex during the event, many of them ending up at the edge of the vortex. Parcels, which began on the $70^{\circ} \mathrm{N}$ circle, were originally within the vortex on 24 January and remained near $70^{\circ}$ or poleward throughout the interval 24 January-3 February. Figure 12 shows the distribution of trajectories on 28 January, when the shape (peanut) of the colored parcels is very similar to that of the vortex edge (black contour; Q-diagnostic); and also on 1 February when the shape of the vortex edge is more symmetrical. At time of release (24 January) the darkest red parcels were in the Scandinavian segment $\left(16^{\circ} \mathrm{E}\right)$ and the lightest green in the Canadian segment $\left(253^{\circ} \mathrm{E}\right)$. By 28 January the air parcels have moved throughout much of the vortex and would be subject to chemical processes including the ozone losses implied by Fig. 11. Note that the air parcels, rich in $\mathrm{O}_{3}$ or not, will have circulated within the vortex and therefore passed several times through regions where there are low temperatures and high probabilities of PSC formation. Availability of solar radiation then allowed for $\mathrm{O}_{3}$ destruction. Rotation times for parcels around the vortex were 3-4 days. Notice that the trajectories took the parcels out of the polar night into these cold regions of cyclonic curvatures, where solar radiation is available even in early February. These regions moved modestly and slowly (vacillations associated with the waves making up the vortex) compared with the speeds of the parcels providing the trajectories in Fig. 12. The angle of maximum elongation for the vortex was relatively constant from 28 January until 4 February. As discussed with regard to Fig. 11, the regions of warmer temperatures are those of anticyclonic curvature rather than cyclonic and are 90 degrees away from the regions of preferred PSC formation $\left(150-180^{\circ} \mathrm{E}\right.$ and $\left.330-360^{\circ} \mathrm{E}\right)$.

\subsection{February event}

We follow a similar process of investigation here as with the earlier event. In Fig. 13 the $r\left(\mathrm{O}_{3}\right)$ distributions are again shown from $475-1200 \mathrm{~K}$ but for three days centred on 25 February, which is at the height of the largest regional 
stratospheric warming in the Pacific-Western Canada (PWC) sector for 2004/2005. As expected from the height-latitude cross-sections of Figs. 5 and 6 , for heights in the middle stratosphere from $\sim 21 \mathrm{~km} / 525 \mathrm{~K}$ to above $38 \mathrm{~km} / 1200 \mathrm{~K}$ ozone has flowed to near the pole for longitudes from western central-Canada (Saskatoon) to the western Pacific (Fig. 13). The cyclonic circulation as characterized by the vortex-edge, which reaches as far south as $45^{\circ}$, limits the access of ozone northward of the edge from eastern-Canada to the Atlantic and as far east as China. Just as for the 1 February event, below $\sim 17 \mathrm{~km}$ there are large $\mathrm{O}_{3}$ mixing ratios at high latitudes within the vortex, while above $24 \mathrm{~km}$ the maximum hemispheric $r\left(\mathrm{O}_{3}\right)$ values are at low latitudes. The shape of the vortex, where it is best defined (525-1200 K), ranges from an off-centered peanut shape to a symmetric off-centered dumbbell, at which times the pole is outside the vortex. Above $\sim 38 \mathrm{~km}$ (not shown) the cyclonic "polar" vortex is located in the Pacific-Western Canada sector at middle latitudes, as is noted in Sect. 4/Fig. 3 where the wind circulations are discussed. The zonal asymmetries of temperatures, winds and vortex thus extended up to the stratopause region at least.

The anticyclones (AC) locations are also added to Fig. 13, using white dashed lines. The dominant AC lies within the Pacific-W. Canada sector and again some higher values of ozone lie near to the $\mathrm{AC}$ regions at $600 \mathrm{~K}(\sim 24 \mathrm{~km})$; lower values of ozone in the $130-200^{\circ} \mathrm{E}$ high latitude sector correspond well with the $\mathrm{AC}$ at $1200 \mathrm{~K}(\sim 38 \mathrm{~km})$ and $800 \mathrm{~K}$ (not shown).

The sequence of latitude-longitude plots ( 21 and 25 February) for $\mathrm{O}_{3}, \mathrm{~T}, \mathrm{ClO}$ and $\mathrm{HNO}_{3}$ at $525 \mathrm{~K}(21 \mathrm{~km})$ are shown in Fig. 14. This is a striking example of intrusion of $\mathrm{O}_{3}$-rich tropical or low latitude air into the polar latitudes, where it became susceptible to incorporation into the vortex. Events occurring on other dates mentioned below are from inspection of plots not included here, but the features mentioned are consistent with those on the two days represented in the figure. The wave-like structure of the vortex edge (white line) is relatively stable in this time interval: within the vortex temperatures are cold (190-195 for 19-25 February, with small areas of $185-190^{\circ}$ ); $\mathrm{ClO}$ is as high as $1.5 \mathrm{ppbv}$ where $\mathrm{O}_{3}$ is as low as 3 ppmv; and $\mathrm{HNO}_{3}$ has maxima where $\mathrm{ClO}$ is large. Creation of $\mathrm{HNO}_{3}$ occurs as $\mathrm{Cl}_{2}$ forms and active $\mathrm{Cl}$ results from photolysis. Certainly, the mid-latitude excursions (as far south as $45^{\circ}$ ) of air parcels within the peanut/dumbell will have brought the air within reach of solar radiation. Assessment of the $475 \mathrm{~K}$ level (not shown) revealed very similar structures of all chemicals: temperatures were as low or lower, and $\mathrm{ClO}$ and $\mathrm{HNO}_{3}$ increases associated with $\mathrm{O}_{3}$ decreases inside the vortex were also very clear. The contextual explanation of Fig. 8 is now much more apparent using Fig. 14. Compared to the stable vortex day of 11 January, processes during the 25 February event provided reduced $\mathrm{O}_{3}$ near $20 \mathrm{~km}$ over Scandinavia-Europe and even extending to eastern Canada e.g. 21 February, due to the regionally localized increases of $\mathrm{ClO}$ (and matching reductions in $\mathrm{HCl}$ in

\section{Average Aura Ozone Mixing Ratio:} 2005 Feb. 24-26 (UT). $\Theta=1200 \mathrm{~K}(\sim 38 \mathrm{Km}) \quad(4.6-7.9)$
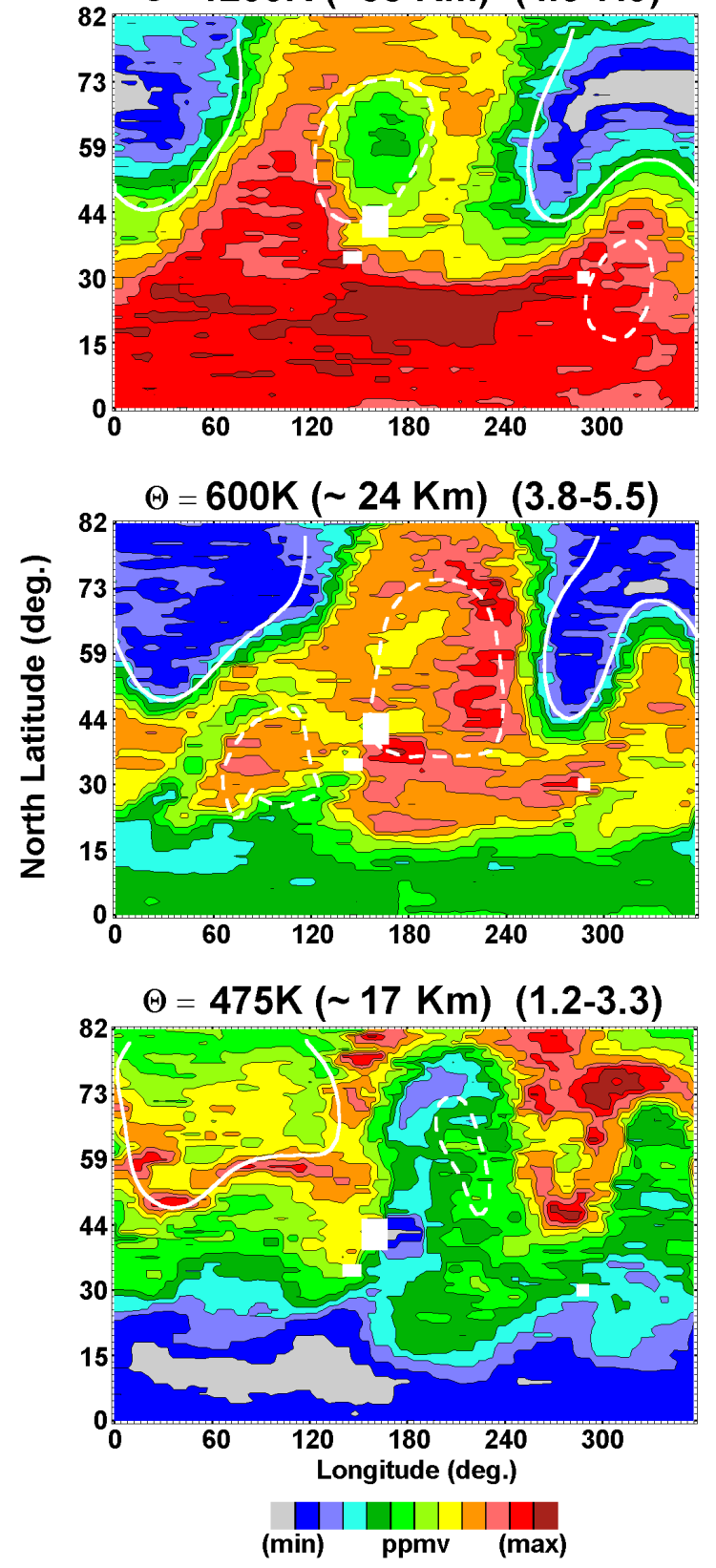

Fig. 13. Polar cylindrical hemispheric contour plots of the 3-day average mixing ratios of ozone (Aura MLS) for three heights. These are for a day (25 February) within the 25 February "warming event" defined in Sect. 3: "the end of a warming trend or "temperature disturbance" (typically $\sim 10$ days in duration) as indicated by zonal mean MetO temperatures at $60-70^{\circ} \mathrm{N}$ and $10 \mathrm{hPa}$ ". The edge of the polar vortex as determined by the Q-diagnostic using MetO (data assimilation model) is shown with a solid white line (see text); the edge of the anticyclone is located with a dashed white line. 


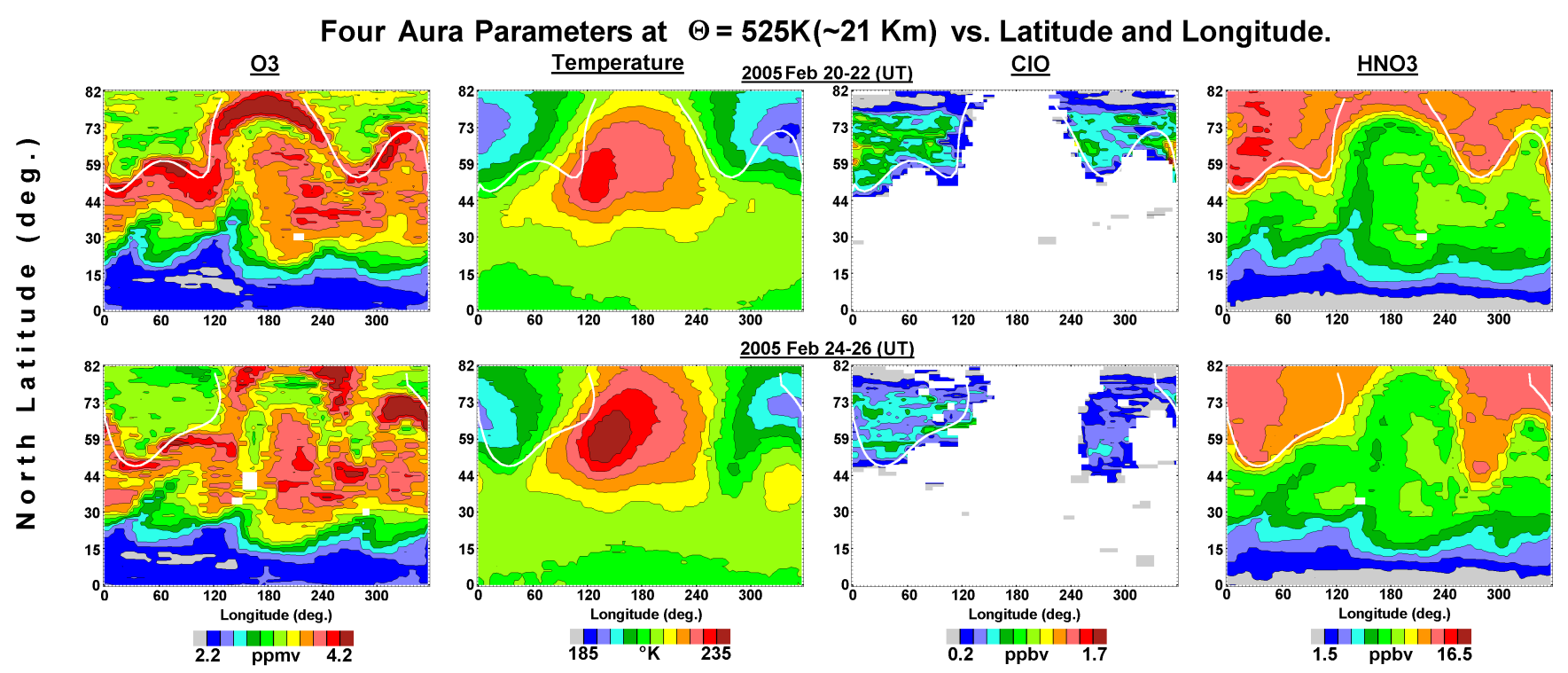

Fig. 14. Polar cylindrical hemispheric contour plots of the 3-day average mixing ratios of ozone, temperature, chlorine monoxide and nitric acid (Aura MLS). These are for two days (21 and 25 February) within the 25 February "warming event" as defined in Sect. 3 . The edge of the polar vortex as determined by the Q-diagnostic using MetO (data assimilation model) is shown in white (see text).

Fig. 8). These chemical changes are in association with low $\mathrm{N}_{2} \mathrm{O}$ (Fig. 8) due to vertical descent in the cyclonic portion of the polar vortex. Notice that the $253^{\circ} \mathrm{E}$ sector through Saskatoon is very close to the vortex edge e.g. on 21 February. The direction of the vortex edge was then close to meridional and provided very strong longitudinal gradients of temperature and constituents; only vortex characterization could place measurements made in middle and eastern Canada in proper context.

Finally, we show two trajectory plots (Fig. 15) to be considered along with Fig. 14. Air parcels were arrayed in a circle at $60^{\circ} \mathrm{N}$ with the red-blue junction near $0^{\circ}$ and the pure-green near mid-Canada. Almost all parcels were outside the vortex edge (black) at the start on 17 February. On 19 February, the edge was already significantly distorted, but trajectory positions show that few parcels penetrated the edge; there were strong $\mathrm{O}_{3}$ losses ( $\mathrm{ClO}$ maxima) at each of the three cyclonic "corners" of this pseudo-triangle. Three similar locations are evident in the polar-cylindrical plot (Fig. 14) of 21 February. However by 27 February, when the vortex had split into two with the stronger and larger cell over Scandinavia-western Europe (Fig. 15), again very few parcels had penetrated the edge. This indicates the continued isolation of the vortex air, as was shown in Figs. 13 and also 14. Meanwhile spatial reductions or losses of $\mathrm{O}_{3}$ on the 27 February were indicated by inspection of plots similar to those in Fig. 14, when low regional values of $\mathrm{O}_{3}$ and high values of $\mathrm{ClO}$ and $\mathrm{HNO}_{3}$ were clearly evident. Generally of course, the hemispheric $\mathrm{O}_{3}$-losses were minimized during the dynamically disturbed days near February 25, as the vortex weakened or became smaller, and temperatures higher.
After this event, the vortex strengthened briefly, but losses of $\mathrm{O}_{3}$ tapered off by early March (near day 11), as discussed by Feng et al. (2007).

\section{Summary and additional comments}

This paper has examined regional changes in temperatures, winds, and chemicals during winter 2004/2005, with emphasis upon three time-intervals which included stratospheric warming events, one of which was a significant regional warming in the Pacific-Western Canada (PWC) sector. This was not a classical Canadian Warming. Atmospheric changes were studied for two longitudinal sectors, which were in western central-Canada and Scandinavia. It has been shown that these changes can only be powerfully organized and understood by the characterization of the polar vortex.

Our study thus follows $\mathrm{C} 07$, which concentrated on the wind fields from troposphere to mesopause regions, and the related characterization of the polar vortex. The winds obtained by way of MetO data as well as calculated from AuraMLS temperatures, and the so-called Q-diagnostic, clearly demonstrated that the polar cyclonic vortex remained strong over Scandinavia and western central-Canada during the 1 February warming. However, the vortex for the lower and middle stratosphere was not present over Canada during the 25 February warming. As this paper was being completed it became clear that five significant aims or goals were imbedded, inherently, within the study. These are provided in the Introduction, and are focused upon within the various sections of the paper. We believe that useful, interesting and 
original materials have been provided on each of the five; and we supply summary material along with other thoughts below.

Firstly, height-latitude contour plots of temperatures (from Aura-MLS) over Scandinavia-Europe $\left(16 \pm 12^{\circ} \mathrm{E}\right)$ and Canada-US $\left(253 \pm 12^{\circ} \mathrm{E}\right)$, along with a zonal mean plot, have demonstrated a very warm and high altitude winter polar stratopause region as well as a warm mesosphere. While the use of the word "stratopause" is not a misnomer, this is a very unique stratopause as solar radiation will not have caused this region of increasing temperature with height, or its peak near $50 \mathrm{~km}$. Rather, dynamical effects such as planetary and/or gravity waves and their dissipation will be involved. This warmer region is not a prominent feature of empirical models such as CIRA-86, or general circulation models (e.g. Manson et al., 2006), unless they include effective tropospheric data assimilation. It seems that the studies of Labitzke (1972) and Hitchman et al. (1989) have been forgotten by some. Strong differences existed between $16^{\circ}$ and $253^{\circ} \mathrm{E}$, during and between the minor or regional warmings centred on 1 February and 25 February, with Scandinavia at $16^{\circ} \mathrm{E}$ having the highest "stratopause" temperatures and coldest lower stratosphere values. This is consistent with Scandinavia being within the stronger portions of the vortex from December through to March, and thus zonal asymmetry being significant for atmospheric properties and processes. This evolving thermal pattern was shown by way of height versus time sequences for locations near those longitudes, and for a range of latitudes.

Secondly, we have demonstrated, using stratospheric zonal mean winds from MetO, that the wind structures for the early winter months of years 2004/2005 and 2005/2006 are consistent with the statistical study by Abatzoglou and Magnusdottir (2007). Their scenario, based upon 25 years of data, is that stronger (winds and vortex) and colder winters (like 2004/2005) should be preceded in November and December by multiple planetary wave breaking (PWB) events at the lower stratospheric levels; while weaker and warmer winters (like 2005/2006) should be preceded by multiple PWB events at upper stratospheric levels (850-1200 K). However we have also shown, as summarized below, that while the winter stratosphere of 2004/2005 was indeed extremely cold and the vortex strong, that vortex was also very disturbed with asymmetries related to very strong Aleutian anticyclones during January and February.

Height versus latitude contours of ozone and related constituents $\left(\mathrm{ClO}, \mathrm{N}_{2} \mathrm{O}\right.$ and $\left.\mathrm{HCl}\right)$ from Aura-MLS were compared during the two warming events providing opportunities to satisfy our third goal. For the 1 February event, when high latitude locations within $25^{\circ}$-wide sectors at $16^{\circ}$ and $253^{\circ} \mathrm{E}$ were within the distorted polar vortex, the edges of the vortex as determined using the Q-diagnostic with MetO data, lay close to the southward edges of the $Q<0$ cyclonic areas. Ozone mixing ratios were generally lower inside the vortex than outside, as expected due to the isolation of the
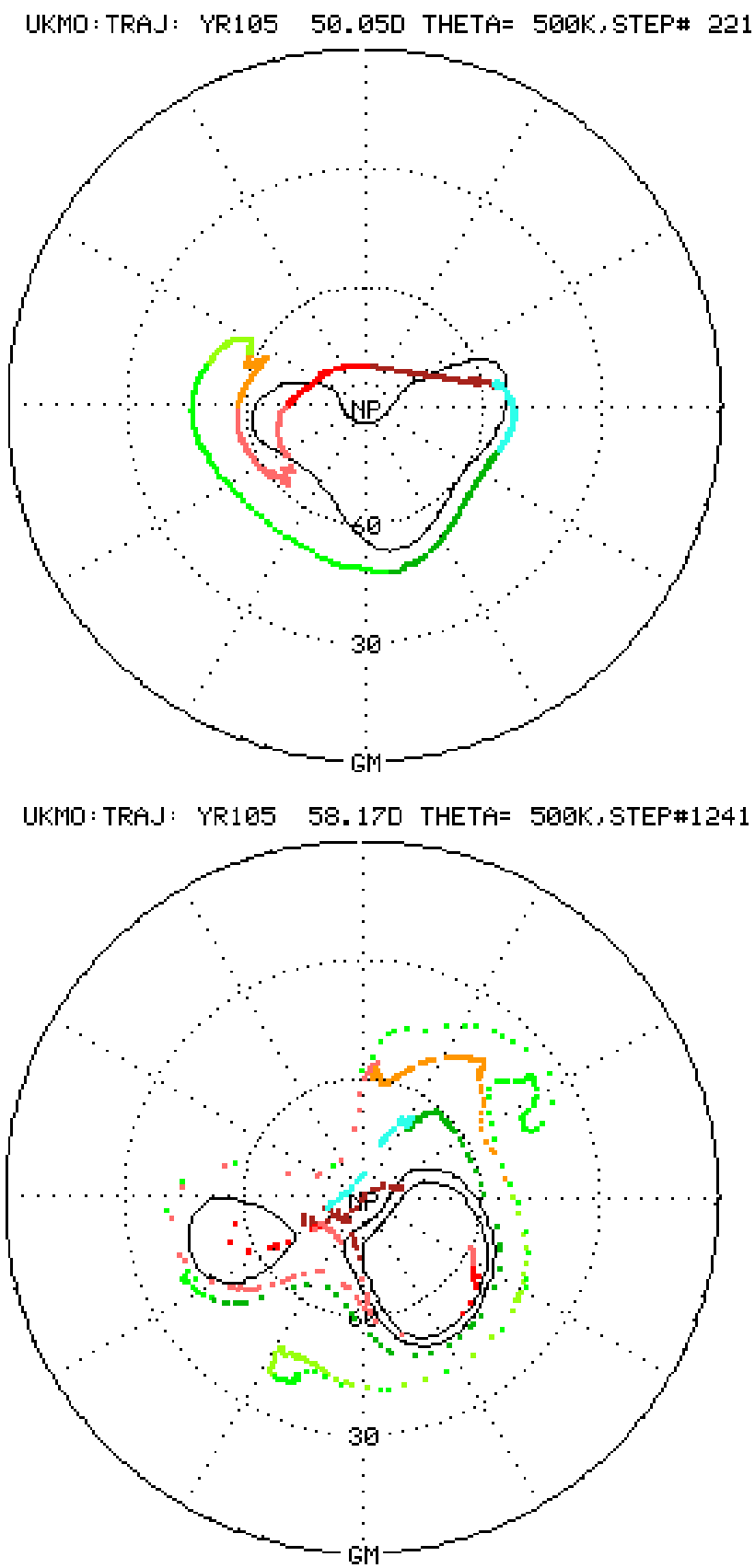

Fig. 15. Trajectory analyses at $500 \mathrm{~K} / 20 \mathrm{~km}$ for two days (19 February and 27 February) within the 25 February temperature/vortex disturbance event of winter 2004/2005. Air parcels were released at the $60^{\circ} \mathrm{N}$ circle on 17 February: burgundy red at $16^{\circ} \mathrm{E}$ and middle/bright green at $253^{\circ} \mathrm{E}$. The vortex edge (from the Qdiagnostic) is shown by the black contour.

polar air. We demonstrated that further significant destruction of vortex-ozone was indicated by the high/low values of $\mathrm{ClO} / \mathrm{O}_{3}$ mixing ratios, at heights near $20 \mathrm{~km}$ and latitudes of $60-70^{\circ} \mathrm{N}$ latitude for the Scandinavia and Canada sectors. For the 25 February event, in terms of mixing ratio 
$(r), \mathrm{O}_{3}$-rich air from lower latitudes continued to be excluded from Scandinavia-Europe throughout the $\sim 10$ days of the event, while tropical $\mathrm{O}_{3}$ penetrated to at least $82^{\circ} \mathrm{N}$ over the west-central Canadian sector. We showed that while losses of ozone near $20 \mathrm{~km}$, associated with Polar Stratospheric Clouds (PSC) and the resulting chlorine monoxide, were clearly indicated over Scandinavia- $16^{\circ} \mathrm{E}$, the advection of ozone to at least $82^{\circ} \mathrm{N}$ and the related absence of the polar vortex dominated the distribution of chemical constituents over Canada.

Finally the changes at these longitudes were placed into a hemispheric context by using polar-cylindrical (latitude versus longitude) contour plots of mixing ratios for $\mathrm{O}_{3}, \mathrm{ClO}$, $\mathrm{HNO}_{3}, \mathrm{HCL}$ and the temperature, consistent with our fourth goal. The edges of the vortex as obtained from the Qdiagnostic are close to being perpendicular to large horizontal gradients of ozone mixing ratios $(r)$. The contoured position and values of these chemicals at heights near $20 \mathrm{~km}$ were very consistent with consensus views of heterogeneous chemistry. The low/high values of $\mathrm{O}_{3} / \mathrm{ClO}$ followed the cyclonic curvatures of the vortex edges, where the adjacent vortex temperatures were low and vertical motions were downward. Meanwhile ozone mixing ratios were unaffected near the anticyclonic curvatures of the vortex edge, where the adjacent vortex temperatures are higher and vertical motions upward. The vortex edge, which was often of peanut or distorted-elliptical shape, was noted to be due to a combination of the stationary planetary waves with wave-numbers $n=1$ and 2 .

Trajectory analysis was applied to both February events at $550 \mathrm{~K}$, near $20 \mathrm{~km}$ altitude, and provided relevant information and understanding as to our fifth goal. A modest cyclonic rotation of the vortex was noted during the 1 February event, while parcels of air circulated within the distorted vortex in 3-4 days. Both of these motions led to air parcels (relatively rich in ozone) passing through low temperature and PSC regions where they experienced heterogeneous chemical processes and destruction. While advection of $\mathrm{O}_{3}$-rich air into the Pacific-Western Canadian sector dominated the 25 February minor warming, the parcel trajectory study provided no evidence for simple entrapment of this air within the vortex. Indeed no other studies of the 2004/2005 events (Sect. 1) claim otherwise. Trajectories of air parcels released at $60^{\circ} \mathrm{N}$ quickly settled into positions near the vortex edge obtained from the Q-diagnostic as applied to MetO data, and continued to do so after the vortex split into two pieces on 27 February. Within the vortex itself, which was often of complex shape, there was evidence for modest loss of $\mathrm{O}_{3}$ compared with the first event, in particular in regions of the vortex with cyclonic curvature and low temperature.

It seems useful to note that studies using equivalent latitudes do unavoidably obscure such regional details of the actual vortex structure and its changes, which are of great interest to at least those who observe certain geographical regions with ground based systems. The equivalent latitude coordi- nate does of course properly account for problems arising from reversible movement of the polar vortex, and is a technique of great value. A major purpose of studies using this technique is to quantify the overall loss of ozone over a given winter-spring, which itself is an enormously important task. Thus we believe that the observations and interpretations reported in this paper, effectively and usefully complement the referenced earlier studies of the complex 2004/2005 middle atmosphere winter.

This study and the earlier results shown in $\mathrm{C} 07$ for the winter of 2004/2005 demonstrate extraordinary and essential longitudinal structure of the stratospheric temperatures, winds, chemicals in that environment, and the polar vortex. Based upon this, and the now completed similar assessment (Chshyolkova et al., 2008) of the winter 2005/2006 that included a major stratospheric warming, it is suggested that atmospheric studies made during winter-centred months at ground-based locations in the Northern and Southern Hemispheres should acknowledge and make use of global information regarding the position and strength of the stratospheric polar vortex. Otherwise interpretations will inevitably be flawed.

Acknowledgements. The authors express their gratitude to V. L. Harvey and T. D. Fairlie for their help with the local development of the Q-diagnostic. Thanks are due to the Aura team for their MLS dataset as well as to the UK Meteorological Office for the stratospheric assimilated data and to the British Atmosphere Data centre for providing access to these data. Funding from the Canadian Granting Agency NSERC, from CANDAC-PEARL through CFCAS, and from the University of Saskatchewan through ISAS is happily noted. AHM thanks his colleague Ted (E. J.) Llewellyn for interesting chats, in particular regarding the ozone mixing ratios in the upper stratosphere (Sect. 6.2, Fig. 10, paragraph 2). We thank Lynn Harvey for her very careful, detailed and philosophically supportive review.

Topical Editor U.-P. Hoppe thanks V. L. Harvey and another anonymous referee for their help in evaluating this paper.

\section{References}

Abatzoglou, J. T. and Magnusdottir, G.: Wave breaking along the stratospheric polar vortex as seen inn ERA-40 data, Geophys. Res. Lett., 34, L08812, doi:10.1029/2007GL029509, 2007.

Akiyoshi, H., Sugata, S., Yoshiki, M., and Sugita, T.: Ozone decrease outside Arctic polar vortex due to polar vortex processing in 1997, J. Geophys. Res., 111, D22311, doi:10.1029/2005JD006540, 2006.

Babiano, A., Boffetta, G., Provenzale, A., and Vulpiani, A.: Chaotic advection in point vortex models and two-dimensional turbulence, Phys. Fluids, 6(7), 2465-2474, 1994.

Choi, W., Kim, S., Grant, W. B., Shiotani, M., Sasano, Y., and Schoeberl, M. R.: Transport of methane in the stratosphere associated with the breakdown of the Antarctic polar vortex, J. Geophys. Res., 107, 8209, doi:10.1029/2001JD000644, 2002.

Chshyolkova, T., Manson, A. H., Meek, C. E., Avery, S. K., Thorsen, D., MacDougall, J. W., Hocking, W., Murayama, Y., 
and Igarashi, K.: Planetary wave coupling in the middle atmosphere (20-90 km): a CUJO study involving TOMS, MetO and MF radar data, Ann. Geophys., 23, 1103-1121, 2005, http://www.ann-geophys.net/23/1103/2005/.

Chshyolkova, T., Manson, A. H., Meek, C. E., Avery, S. K., Thorsen, D., MacDougall, J. W., Hocking, W., Murayama, Y., and Igarashi, K.: Planetary wave coupling processes in the middle atmosphere (30-90 km): a study involving MetO and MF radar data, J. Atmos. Solar-Terr. Phys., 68, 353-368, 2006.

Chshyolkova, T., Manson, A. H., Meek, C. E., Aso, T., Avery, S. K., Hall, C. M., Hocking, W., Igarashi, K., Jacobi, C., Makarov, N., Mitchell, N., Murayama, Y., Singer, W., Thorsen, D., and Tsutsumi, M.: Polar Vortex Evolution during Northern Hemispheric Winter 2004/05, Ann. Geophys., 25, 1279-1298, 2007, http://www.ann-geophys.net/25/1279/2007/.

Chshyolkova, T., Manson, A. H., Meek, C. E., Jacobi, C., Hall, C. M., and Thorsen, D.: Middle Atmosphere dynamics and its effects on distribution of chemical constituents during $\mathrm{NH}$ winter of 2005/06, Ann. Geophys., submitted, 2008.

Fairlie, T. D. A.: Three-dimensional transport simulations of the dispersal of volcanic aerosol from Mount Pinatubo, Q. J. Roy. Meteorol. Soc., 121(528), 1943-1980, doi:10.1256/smsqj.52808, 1995.

Feng, W., Chipperfield, M. P., Davies, S., von der Gathen, P., Kyrö, E., Volk, C. M., Ulanovsky, A., and Belyaev, G.: Large chemical ozone loss in 2004/2005 Arctic winter/spring, Geophys. Res. Lett., 34, L09803, doi:10.1029/2006GL029098, 2007.

Froidevaux, L., Livesey, N. J., Read, W. G., Jiang, Y. B, Jimenez, C. C., Filipiak, M. J., Schwartz, M. J., Santee, M. L., Pumphrey, H. C., and Jiang, J. H.: Early validation analyses of atmospheric profiles from EOS MLS on the Aura satellite, IEICE Transactions on Communications, 44(5), 1106-1121, 2006.

Gregory, J. B. and Manson, A. H.: Seasonal Variations of Electron Densities Below $100 \mathrm{~km}$ at Mid-latitudes. III. Stratosphericionospheric Coupling, J. Atmos. Solar-Terr. Phys., 32, 837-852, 1970.

Gregory, J. B. and Manson, A. H.: Winds and Wave Motions to $110 \mathrm{~km}$ at Mid-latitudes. III. Response of Mesospheric and Thermospheric Winds to Major Stratospheric Warmings, J. Atmos. Sci., 32, 1676-1681, 1975.

Grooß, J.-U. and Müller, R.: Simulation of ozone loss in Arctic winter 2004/2005, Geophys. Res. Lett., 34, L05804, doi:10.1029/2006GL028901, 2007.

Harvey, V. L., Pierce, R. B., Fairlie, T. D., and Hitchman, M. H.: A climatology of stratospheric polar vortices and anticyclones, J. Geophys. Res., 107(D20), 4442, doi:10.1029/2001JD001471, 2002.

Harvey, V. L., Pierce, R. B., Hitchman, M. H., et al.: On the distribution of ozone in stratospheric anticyclones, J. Geophys. Res.Atmos., 109(D24), D24308, doi:10.1029/2004JD004992, 2004.

Hitchman, M. H., Gille, J. C., Rodgers, C. D., and Brasseur, G.: The Separated Polar Winter Stratopause: A Gravity Wave Driven Climatological Feature, J. Atmos. Sci., 46(3), 410-421, 1989.

Hocking, W.: Middle atmosphere dynamical studies at Resolute Bay over a full representative year: Mean winds, tides, and special oscillations, Radio Sci., 36(6), 1795-1822, 2001.

Holton, J. R. and Tan, H. C.: The influence of the Equatorial Quasibiennial Oscillation on the Global Circulation at $50 \mathrm{MB}$, J. Atmos. Sci., 37(10), 2200-2208, 1980.
Jiménez, C., Pumphrey, H. C., MacKenzie, I. A., Manney, G. L., Santee, M. L., Schwartz, M. J., Harwood, R. S., and Waters, J. W.: EOS MLS observations of dehydration in the 2004-2005 polar winters, Geophys. Res. Lett., 33(16), L16806, doi:10.1029/2006GL025926, 2006.

Karpetchko, A., Kyrö, E., and Knudsen, B. M.: Arctic and Antarctic polar vortices 19572002 as seen from the ERA-40 reanalyses, J. Geophys. Res., 110, D21109, doi:10.1029/2005JD006113, 2005.

Keil, M., Jackson, D. R., and Hort, M. C.: The January 2006 low ozone event over the UK, Atmos. Chem. Phys., 7, 961-972, 2007, http://www.atmos-chem-phys.net/7/961/2007/.

Kent, G. S., Poole, L. R., and McCormick, M. P.: Characteristics of Arctic Polar Stratospheric Clouds as measured by Airborne Lidar, J. Atmos. Sci., 43(20), 2149-2161, 1985.

Labitzke, K.: Temperature changes in the mesosphere and stratosphere connected with circulation changes in winter, J. Atmos. Sci., 29(4), 756-766, 1972.

Labitzke, K.: Interannual variability of the winter stratosphere in the Northern Hemisphere, Mon. Weather Rev., 105, 762-770, 1977.

Labitzke, K., Manson, A. H., Barnett, J. J., and Corney, M.: Comparison of Geostrophic and Observed Winds in the Upper Mesosphere over Saskatoon, Canada., J. Atmos. Solar-Terr. Phys., 49, 987-997, 1987.

Labitzke, K., Kunzel, M., and Broonnimann, S.: Sunspots, the QBO and the stratosphere in the North Polar Region - 20 years later, Meteor. Atmos. Sci., 15(3), 355-363, 2006.

Labitzke, K. and Kunze, M.: Major Midwinter Warming in Stratosphere in 2005/2006, CAWSES News, 3(2), 6-7, September 2006.

Lorenc, A. C., Ballard, S. P., Bell, R. S., Ingleby, N. B., Andrews, P. L. F., Barker, D. M., Bray, J. R., Clayton, A. M., Dalby, T. Li, D., Payne T. J., and Saunders, F. W.: The Met. Office global threedimensional variational data assimilation scheme, Q. J. Roy. Meteorol. Soc., Part B, 126(570), 2991-3012, 2000.

Manney, G. L., Zurek, R. W., O'Neill, A., et al.: Stratospheric warmings during February and March 1993, Geophys. Res. Lett., 21, 813-816, 1994.

Manney, G. L., Froidevaux, L., Waters, J. W., et al.: Formation of Low-Ozone Pockets in the Middle Stratospheric Anticyclone during Winter, J. Geophys. Res.-Atmos., 100(D7), 13 939$13950,1995$.

Manney, G. L., Santee, M. L., Froidevaux, L., Hoppel, K., Livesey, N. J., and Waters, J. W.: EOS MLS observations of ozone loss in the 2004-2005 Arctic winter, Geophys. Res. Lett., 33(4), L04802, doi:10.1029/2005GL024494, 2006.

Manson, A. H., Meek, C. E., Stegman, J., Espy, P. J., Roble, R. G., Hall, C. M., Hoffman, P., and Jacobi, Ch.: Springtime transition in mesopause airglow and dynamics: photometer and MF Radar observations in the Scandinavian and Canadian sectors, J. Atmos. Sol.-Terr. Phys., 64, 1131-1146, 2002.

Manson, A. H., Meek, C. E., Avery, S. K., and Thorsen, D.: Ionospheric and dynamical characteristics of the mesosphere-lower thermosphere region over Platteville $\left(40^{\circ} \mathrm{N}, 105^{\circ} \mathrm{W}\right)$ and comparisons with the region over Saskatoon $\left(52^{\circ} \mathrm{N}, 107^{\circ} \mathrm{W}\right)$, J. Geophys. Res., 108(D13), 4398, doi:10/1029/2002JD002835, 2003.

Manson, A. H., Meek, C. E., Chshyolkova, T., Avery, S. K., Thorsen, D., MacDougall, J. W., Hocking, W., Murayama, Y., Igarashi, K., Namboothiri, S. P., and Kishore, P.: Longitudi- 
nal and Latitudinal Variations in Dynamic Characteristics of the MLT (70-95 km): A Study Involving the CUJO network, Ann. Geophys., 22, 347-365, 2004, http://www.ann-geophys.net/22/347/2004/.

Manson, A. H., Meek, C. E., Chshyolkova, T., et al.: Wave activity (planetary, tidal) throughout the middle atmosphere $(20-100 \mathrm{~km})$ over the CUJO network: Satellite (TOMS) and Medium Frequency (MF) radar observations, Ann. Geophys., 23, 305-323, 2005, http://www.ann-geophys.net/23/305/2005/.

Manson, A. H., Meek, C., Chshyolkova, T., McLandress, C., Avery, S. K., Fritts, D. C., Hall, C. M., Hocking, W. K., Igarashi, K., MacDougall, J. W., Murayama, Y., Riggin, D. C., Thorsen, D., and Vincent, R. A.: Winter warmings, tides and planetary waves: comparisons between CMAM (with interactive chemistry) and MFR-MetO observations and data, Ann. Geophys., 10, 24932518, 2006, http://www.ann-geophys.net/10/2493/2006/.

McIntyre, M. E. and Palmer, T. N.: Breaking planetary waves in the stratosphere, Nature, 305, 593-600, 1983.

Morris, G. A., Kawa S. R., Douglass A. R., et al.: Low-ozone pockets explained, J. Geophys. Res.-Atmos., 103(D3) 3599-3610, 1998.

O’Neill, A., Grose, W. L., Pope, V. D., Maclean, H., and Swinbank, R.: Evolution of the Stratosphere during Northern Winter 1991/92 as Diagnosed from UK-Meteorological-Office Analyses, J. Atmos. Sci., 51(20), 2800-2817, 1994.

Polvani, L. P. and Saravanan, R.: The thee-dimensional structure of breaking Rossby waves in the polar wintertime stratosphere, J. Atmos. Sci., 57, 3663-3685, 2000.

Randel, W., Udelhofen, P., Fleming, E., Geller, M., Gelman, M., Hamilton, K., Karoly, D., Ortland, D., Pawson, S., Swinbank, R., Wu, F., Baldwin, M., Chanin, M.-L., Keckhut, P., Labitzke, K., Remsberg, E., Simmons, A., and Wu, D.: The SPARC intercomparison of middle-atmosphere climatologies, J. Climate, 17(5), 986-1003, 2004.

Salby, M. L.: Fundamentals of Atmospheric Physics, San Diego, Calif., Academic Press, Inc., pp. 627, 1996.
Salby, M. L. and Callaghan, P. F.: Residual mean transport in the stratosphere: Contributions from wave driving and seasonal transience, J. Geophys. Res., 111, D22304, doi:10.1029/2005JD006767, 2006.

Salby, M. L. and Callaghan, P. F.: On the wintertime increase of Arctic ozone: Relationship to Changes of the polarnight vortex, J. Geophys. Res.-Atmos., 112(D6), D06116, doi:10.1029/2006JD007948, 2007.

Singleton, C. S., Randall, C. E., Harvey, V. L., Chipperfield, M. P., Feng, W., Manney, G. L., Froidevaux, L., Boone, C. D., Bernath, P. F., Walker, K. A., McElroy, C. T., and Hoppel, K. W.: Quantifying Arctic ozone loss during the 2004-2005 winter using satellite observations and chemical transport model, J. Geophys. Res., 112, D07304, doi:10.1029/2006JD007463, 2007.

Siskind, D. E., Eckermann, S. D., Coy, L., McCormack, J. P., and Randall, C. E.: On recent interannual variability of the Arctic winter mesosphere: Implications for tracer descent, Geophys. Res. Lett., 34, L09806, doi:10.1029/2007GL029293, 2007.

Tilmes, S., Müller, R., Grooß, J.-U., Nakajima, H., and Sasano, Y.: Development of tracer relations and chemical ozone loss during the setup phase of the polar vortex, J. Geophys. Res., 111, D24S90, doi:10.1029/2005JD006726, 2006.

von Hobe, M., Ulanovsky, A., Volk, C. M., Grooß, J.-U., Tilmes, S., Konopka, P., Günther, G., Werner, A., Spelten, N., Shur, G., Yushkov, V., Ravegnani, F., Schiller, C., Müller, R., and Stroh, F.: Severe ozone depletion in the cold Arctic winter 2004-05, Geophys. Res. Lett., 33, L17815, doi:10.1029/2006GL026945, 2006.

Waters, J. W., Froidevaux, L., Harwood, R. S., Jarnot, R. F., Pickett, H. M., Read, W. G., Siegel, P. H., Cofield, R. E., Filipiak, M. J., and Flower, D. A.: The Earth Observing System Microwave Limb Sounder (EOS MLS) on the Aura satellite, IEEE Trans. Geosci. Rem. Sens., 44(5), 1075-1092, 2006. 